\title{
Lipids bearing extruded-spheronized pellets for extended release of poorly soluble antiemetic agent-Meclizine $\mathrm{HCl}$
}

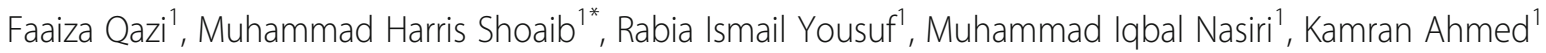
and Mansoor Ahmad²

\begin{abstract}
Background: Antiemetic agent Meclizine $\mathrm{HCl}$, widely prescribed in vertigo, is available only in immediate release dosage forms. The approved therapeutic dose and shorter elimination half-life make Meclizine $\mathrm{HCl}$ a potential candidate to be formulated in extended release dosage form. This study was aimed to develop extended release Meclizine $\mathrm{HCl}$ pellets by extrusion spheronization using natural and synthetic lipids. Influence of lipid type, drug/ lipid ratio and combinations of different lipids on drug release and sphericity of pellets were evaluated.
\end{abstract}

Methods: Thirty two formulations were prepared with four different lipids, Glyceryl monostearate (Geleol'), Glyceryl palmitostearate (Precirol ${ }^{\circ}$ ), Glyceryl behenate $\left(\right.$ Comprito $^{\circ}$ ) and Carnauba wax, utilized either alone or in combinations of drug/lipid ratio of 1:0.5-1:3. Dissolution studies were performed at variable $\mathrm{pH}$ and release kinetics were analyzed. Fourier transform infrared spectroscopy was conducted and no drug lipid interaction was found.

Results: Sphericity indicated by shape factor $\left(e_{R}\right)$ varied with type and concentration of lipids: Geleol $\left(e_{R}=0.891-0.997\right)$, Precirol $^{\circ}\left(e_{R}=0.611-0.743\right)$, Compritol ${ }^{\circ}\left(e_{R}=0.665-0.729\right)$ and Carnauba wax $\left(e_{R}=0.499-0.551\right)$. Highly spherical pellets were obtained with Geleol (Aspect ratio $=1.005-1.052$ ) whereas irregularly shaped pellets were formed using Carnauba wax (Aspect ratio $=1.153-1.309$ ). Drug release was effectively controlled by three different combinations of lipids: (i) Geleol $^{\circ}$ and Compritol', (ii) Geleol and Carnauba wax and (iii) Geleol', Compritol and Carnauba wax. Scanning electron microscopy of Compritol pellets showed smooth surface with pores, whereas, irregular rough surface with hollow depressions was observed in Carnauba wax pellets. Energy dispersive spectroscopy indicated elemental composition of lipid matrix pellets. Kinetics of (i) Geleol and Compritol pellets, explained by Korsmeyer-Peppas $\left(R^{2}=0.978-0.993\right)$ indicated non-Fickian diffusion ( $n=0.519-0.597)$. Combinations of (ii) Geleol and Carnauba wax and (iii) Geleol', Compritol and Carnauba wax pellets followed Zero-order $\left(R^{2}=0.991-0.995\right)$. Similarity test was performed using combination of Geleol ${ }^{\circ}$ and Compritol ${ }^{\circ}$ (i) as a reference.

Conclusions: Matrices for the extended release of Meclizine $\mathrm{HCl}$ from extruded-spheronized pellets were successfully formed by using three lipids (Geleol ${ }^{\circ}$, Compritol and Carnauba wax) in different combinations. The encapsulated pellets of Meclizine $\mathrm{HCl}$ can be effectively used for treatment of motion sickness, nausea and vertigo for extended period of time.

Keywords: Meclizine $\mathrm{HCl}$, Pellets, Lipids, Extended release, Extrusion spheronization

\footnotetext{
* Correspondence: harrisshoaib2000@yahoo.com

'Department of Pharmaceutics, Faculty of Pharmacy \& Pharmaceutical

Sciences, University of Karachi, Karachi 75270, Pakistan

Full list of author information is available at the end of the article
} 


\section{Background}

Meclizine $\mathrm{HCl}$ is a histamine $\left(\mathrm{H}_{1}\right)$ receptor antagonist, indicated for prophylactic treatment and management of vomiting, nausea and dizziness due to motion sickness. It is also indicated for pruritus, anaphylactic reactions and vertigo associated with diseases affecting the vestibular system (e.g., Meniere disease, labyrinthitis) [1, 2]. It is more frequently prescribed because of fewer adverse effects [1]. It ranks among the top 200 drugs of 2014 as per total prescription count [3]. It is currently available as immediate release tablets, capsules and chewable tablets [1]. It is not available as an extended release (ER) dosage form. Literature survey results show that lipid based ER pellets of Meclizine $\mathrm{HCl}$ have not been reported yet. Meclizine $\mathrm{HCl}$ has a plasma elimination half-life of 5-6 h $[1,2]$. For the treatment of vertigo, the standard dose is $25-100 \mathrm{mg} /$ day, given in two or more divided doses [4]. ER formulation of Meclizine $\mathrm{HCl}$ is thus, required to enhance patient compliance while reducing dosing intervals and minimizing risk of dose related adverse effects.

In comparison to monolithic system, pellets provide added benefits of multiple unit dosage forms. They are rapidly dispersed in gastrointestinal tract and enhance drug absorption and bioavailability. Use of pellets reduce peak plasma fluctuations and minimize risk of dose dumping. Pellet formulations also have provision of further modifications $[5,6]$. Clinical studies demonstrate that pellets provide flexibility in doses by variations in the amount of administered drug [6]. Different techniques are available for manufacturing of pellets such as layering of drug cores in a fluid bed coater, extrusion spheronization, melt pelletization and direct pelletization in a rotary processor or high shear mixer. Although, melt granulation is the most commonly reported method for pelletization of lipids [7-11] but it may lead to drug stability issues because the powder mass is melted at high temperature [12]. Extrusion spheronization method followed by wet granulation, is preferred for the preparation of extended release pellets. This technique is reported to be the most robust and reproducible means for the preparation of multiparticulates (pellets) with spherical shape, high density, low friability, high drug loading capacity and good flow properties in a reasonable time $[6,13]$.

In oral drug delivery system, lipids are successfully used to enhance swallowability, shelf life, provision of modified release profiles, taste masking, reduction of gastric irritation and to improve bioavailability of poorly soluble drugs [14]. Meclizine $\mathrm{HCl}$, a Biopharmaceutics classification system (BCS) class II agent, is attributed with low solubility and high permeability [15]. Increased bioavailability and prolonged drug delivery of Meclizine $\mathrm{HCl}$ can be achieved by preparation of lipids bearing extruded-spheronized pellets because of the resemblance of lipids to in vivo components and its unique set of physiochemical properties [16].

Glyceryl monostearate, GMS (Geleol ), Glyceryl palmitostearate, GPS (Precirol), and Glyceryl behenate, GB (Compritol ) are three of the lipid glycerides, which form lipid matrices owing to their high melting points and are recommended for sustained delivery of drugs [17]. They are reported to be effective release retardants in ER dosage forms [7-10, 16]. GMS (Geleol ) is a mono glyceride of stearic acid having two free hydroxyl groups [10]. GPS (Precirol ${ }^{\circ}$ ) is a combination of glycerides (mono, di and tri) of palmitic acid and stearic acid. GB (Compritol ${ }^{\circ}$ ) is a mixture of mono, di and tri behenate of glycerol, prepared by the esterification of behenic acid (C22) with glycerine. GPS (Precirol ) and GB (Compritol) have low HLB value (2), indicating marked hydrophobicity of these two glycerides due to the absence of polyethylene glycol esters and esterification of glycerol by long chain fatty acids [8]. Another promising lipid excipient to extend the release is Carnauba wax [14]. Carnauba wax is mainly composed of esters of carboxylic acid (C24 and C28) and straight chain primary alcohols (C32 and C34) [18]. It controls drug release through pore diffusion and erosion when applied as a coating polymer or used as a matrix former [5, 18-20].

The objective of this study was to formulate ER pellets of Meclizine $\mathrm{HCl}$ by extrusion spheronization method using matrices of GMS (Geleol'), GPS (Precirol'), GB (Compritol) and Carnauba wax. The influence of lipid type, drug/lipid ratio and combination of lipids on drug release and sphericity of pellets were evaluated. Drug excipient interaction was determined by Fourier transform infrared (FTIR) spectroscopy. Elemental characterization was carried out by Energy dispersive spectroscopy (EDS) along with Scanning electron microscopy (SEM) to reveal the surface morphology of pellets. In vitro dissolution was performed at variable $\mathrm{pH}(1.2,4.5$ and 6.8) and release profiles were evaluated using different kinetic models. Accelerated stability was also conducted for optimized formulations.

\section{Materials and methods Materials}

Meclizine $\mathrm{HCl}$ was a gift from Ali Gohar Pharmaceuticals Private Limited (Pakistan). Lipids: GMS (Geleol 40-55, type I), GPS (Precirol ATO5), GB (Compritol888ATO) were obtained from Gattefosse Foundation (Saint-Priest, France). CW was provided by BDH laboratory suppliers (England). Microcrystalline Cellulose, MCC (Avicel PH-101) was purchased from FMC Corporation (USA). Freshly prepared distilled water (DW) was used and all analytical grade reagents and solvents were utilized. 


\section{Methods}

\section{Dose calculation}

The dose for ER Meclizine $\mathrm{HCl}$ was calculated from the given formula:

$$
D_{t}=\text { Dose }\left(1+0.693 \times{ }^{t} / t_{1 / 2}\right)
$$

Where, $D_{t}$ is total dose, $t$ is time for extended drug release i.e. $12 \mathrm{~h}$ and $t_{1 / 2}$ is the drug half-life [21]. Thus, by applying the above equation, extended release dose of Meclizine $\mathrm{HCl}$ is found to be $60 \mathrm{mg}$.

\section{Experimental design}

Different blends of Meclizine $\mathrm{HCl}$ (60 mg) were prepared using MCC (spheronizing aid), Geleol, Precirol, Compritol and CW (release controlling lipids). The experiments were conducted in four groups: Group 1 based on single lipid; Group 2: combination of two lipids; Group 3: combination of three lipids; Group 4: combination of four lipids. Thirty two formulations were designed. These formulations were based on drug/lipid ratio of 1:1-1:3 except Group 1 in which the drug/lipid ratio was 1:0.5-1:2. MCC concentration was fixed to provide identical plasticity upon extrusion and brittleness during spheronization (Table 1). Group 1 formulations were prepared for initial screening of four different lipids (Geleol', Precirol, $\mathrm{Compritol}^{\circ}$ and $\mathrm{CW}$ ) and their individual effect on release of Meclizine $\mathrm{HCl}$ and sphericity of pellets. Drug/lipid ratio of 1:0.5-1:2 was selected from relevant published studies $[18,22,23]$. Further Groups were designed on the basis of Group 1 findings in which drug/lipid ratio was increased to $1: 3$ and combination of lipids were used $[19,24]$.

\section{Preparation of extended release pellets}

Lipids were pulverized in a mortar and pestle. Hard CW was difficult to grind due to its plastic nature. Drug and excipients were weighted after passing through 40 mesh sieve (American Society of Testing and Materials, ASTM) and were blended dry for $10 \mathrm{~min}$ in a planetary mixer. Mixed powder was granulated using DW. Quantity of DW was adjusted based on preliminary experiments to achieve the spherical pellets and maximum yield. DW was poured gradually and wet mixing was continued until homogenous and cohesive mass was achieved. Uniform water distribution was ensured by repeatedly scrapping sides of the bowl. The wet mass was immediately processed with laboratory screw extruder (Caleva Process Solution Ltd., UK) fitted with screen $(1 \mathrm{~mm})$, operated at 50-60 rpm. Extrudes were collected in a tray, broken down manually into small cylinders and then spheronized (Caleva Process Solution Ltd., UK) for $10 \mathrm{~min}$ at 600-800 rpm. The wet pellets were dried in an oven for $12 \mathrm{~h}$ at $40{ }^{\circ} \mathrm{C}$ [13]. Dried screened pellets were filled into 0 size hard gelatin capsule shells.

\section{Fourier transform infrared spectroscopy (FTIR)}

Pure drug and optimized formulations were subjected to IR spectroscopy using FTIR spectrophotometer (Thermo Nicolet Avatar, 330) to determine interactions between active drug and excipients. Spectra were scanned from 4000 to $500 \mathrm{~cm}-1$ wave number using OMNIC ${ }^{\mathrm{mM}}$ Spectra Software.

\section{Moisture content and size of pellets}

Water content of pellets immediately after spheronization and drying were determined in each batch. Samples were placed on petri dishes and heated to $40{ }^{\circ} \mathrm{C}$ in a hot air oven until the moisture content (MC) became constant. Pellets were sieved using sieve shaker containing nest of standard sieves for $10 \mathrm{~min}$. Pellets retained on each sieve were weighed. Size in the range of $800-1500 \mu \mathrm{m}$ was considered appropriate and utilized for further studies.

\section{Flow properties of pellets}

Forty gram pellets from each batch were placed in a $100 \mathrm{ml}$ measuring cylinder. Initial and tapped volumes were recorded. Static angle of repose was determined by measuring height of symmetrical cone of pellets formed through a funnel at a fixed base. Mean and standard deviation of three readings were used.

$$
\begin{aligned}
& \text { Bulk density }=\frac{M}{V_{o}} \\
& \text { Tapped density }=\frac{M}{V_{f}} \\
& \text { Compressibility Index }=\left(\frac{V_{o}-V_{f}}{V_{o}}\right) \times 100 \\
& \text { Hausner ratio }=\frac{V_{o}}{V_{f}} \\
& \tan _{(\alpha)}=\frac{\text { height }}{0.5 \text { base }}
\end{aligned}
$$

Where, $M$ is the mass of pellets, $V_{o}$ and $V_{f}$ are the bulk and tapped volumes of pellets respectively. Compressibility index $11-15$ and hausner ratio $1.12-1.18$ show good flow properties, whereas, compressibility index $\leq 10$ and hausner ratio 1.00-1.11 exhibit excellent flow properties. Angle of repose shows good flow from 31 to 35 and excellent flow from 25 to 30 [25].

\section{Friability of pellets}

$10 \mathrm{~g}$ pellets were placed in a friabilator wheel (Erweka GmbH D-63150, Husenstamm, Germany) and subjected to falling shocks at $25 \mathrm{rpm}$ for $4 \mathrm{~min}$. $250 \mu \mathrm{m}$ mesh was used to remove fines and the friability was calculated by remaining above fraction. 
Table 1 Composition of $60 \mathrm{mg}$ Meclizine $\mathrm{HCl}$ ER matrix pellets formulations

\begin{tabular}{|c|c|c|c|c|c|c|c|c|c|c|c|c|c|c|}
\hline \multirow[t]{2}{*}{ Groups } & \multirow[t]{2}{*}{ Codes } & \multirow{2}{*}{$\begin{array}{l}\text { Drug: } \\
\text { Lipid } \\
\text { Ratio }\end{array}$} & \multicolumn{2}{|c|}{ Geleol $^{\oplus}$} & \multicolumn{2}{|c|}{ Precirol $^{\otimes}$} & \multicolumn{2}{|c|}{$\mathrm{Compritol}^{\oplus}$} & \multicolumn{2}{|c|}{ Carnauba Wax } & \multicolumn{2}{|c|}{ MCC } & \multirow{2}{*}{$\begin{array}{l}\text { Granulating Fluid } \\
\%\end{array}$} & \multirow{2}{*}{$\begin{array}{l}\text { Total wt } \\
\text { mg }\end{array}$} \\
\hline & & & $\mathrm{mg}$ & $\%$ & $\mathrm{mg}$ & $\%$ & $\mathrm{mg}$ & $\%$ & $\mathrm{mg}$ & $\%$ & $\mathrm{mg}$ & $\%$ & & \\
\hline \multirow[t]{12}{*}{ Group 1: Single Lipids } & F1 & $1: 0.5$ & 30 & 20 & - & - & - & - & - & - & 60 & 40 & 39 & 150 \\
\hline & F2 & $1: 1$ & 60 & 30 & - & - & - & - & - & - & 80 & 40 & 33 & 200 \\
\hline & F3 & $1: 2$ & 120 & 40 & - & - & - & - & - & - & 120 & 40 & 30 & 300 \\
\hline & $\mathrm{F} 4$ & $1: 0.5$ & - & - & 30 & 20 & - & - & - & - & 60 & 40 & 44 & 150 \\
\hline & F5 & $1: 1$ & - & - & 60 & 30 & - & - & - & - & 80 & 40 & 39 & 200 \\
\hline & F6 & $1: 2$ & - & - & 120 & 40 & - & - & - & - & 120 & 40 & 33 & 300 \\
\hline & F7 & $1: 0.5$ & - & - & - & - & 30 & 20 & - & - & 60 & 40 & 43 & 150 \\
\hline & F8 & $1: 1$ & - & - & - & - & 60 & 30 & - & - & 80 & 40 & 41 & 200 \\
\hline & F9 & $1: 2$ & - & - & - & - & 120 & 40 & - & - & 120 & 40 & 33 & 300 \\
\hline & F10 & $1: 0.5$ & - & - & - & - & - & - & 30 & 20 & 60 & 40 & 41 & 150 \\
\hline & F11 & $1: 1$ & - & - & - & - & - & - & 60 & 30 & 80 & 40 & 33 & 200 \\
\hline & $\mathrm{F} 12$ & $1: 2$ & - & - & - & - & - & - & 120 & 40 & 120 & 40 & 28 & 300 \\
\hline \multirow[t]{8}{*}{ Group 2: Two Lipids Combinations } & F13 & $1: 1$ & 20 & 10 & 60 & 30 & - & - & - & - & 60 & 30 & 35 & 200 \\
\hline & F14 & $1: 2$ & 20 & 10 & 100 & 50 & - & - & - & - & 20 & 10 & 29 & 200 \\
\hline & F15 & $1: 3$ & 30 & 10 & 180 & 60 & - & - & - & - & 30 & 10 & 26 & 300 \\
\hline & F16 & $1: 1$ & 20 & 10 & - & - & 60 & 30 & - & - & 60 & 30 & 35 & 200 \\
\hline & F17 & $1: 2$ & 20 & 10 & - & - & 100 & 50 & - & - & 20 & 10 & 29 & 200 \\
\hline & F18 & $1: 3$ & 30 & 10 & - & - & 180 & 60 & - & - & 30 & 10 & 24 & 300 \\
\hline & F19 & $1: 1$ & 20 & 10 & - & - & - & - & 60 & 30 & 60 & 30 & 27 & 200 \\
\hline & F20 & $1: 2$ & 20 & 10 & - & - & - & - & 100 & 50 & 20 & 10 & 23 & 200 \\
\hline \multirow[t]{9}{*}{ Group 3: Three Lipids Combinations } & F21 & $1: 1$ & 20 & 10 & 20 & 10 & 20 & 10 & - & - & 80 & 40 & 31 & 200 \\
\hline & F22 & $1: 2$ & 40 & 20 & 40 & 20 & 40 & 20 & - & - & 20 & 10 & 27 & 200 \\
\hline & F23 & $1: 3$ & 60 & 20 & 60 & 20 & 60 & 20 & - & - & 60 & 20 & 22 & 300 \\
\hline & F24 & $1: 1$ & 20 & 10 & 20 & 10 & - & - & 20 & 10 & 80 & 40 & 27 & 200 \\
\hline & F25 & $1: 2$ & 40 & 20 & 40 & 20 & - & - & 40 & 20 & 20 & 10 & 22 & 200 \\
\hline & F26 & $1: 3$ & 60 & 20 & 60 & 20 & - & - & 60 & 20 & 60 & 20 & 20 & 300 \\
\hline & $F 27$ & $1: 1$ & 20 & 10 & - & - & 20 & 10 & 20 & 10 & 80 & 40 & 29 & 200 \\
\hline & F28 & $1: 2$ & 40 & 20 & - & - & 40 & 20 & 40 & 20 & 20 & 10 & 26 & 200 \\
\hline & F29 & $1: 3$ & 60 & 20 & - & - & 60 & 20 & 60 & 20 & 60 & 20 & 20 & 300 \\
\hline \multirow[t]{3}{*}{ Group 4: Four Lipids Combinations } & F30 & $1: 1$ & 15 & 8 & 15 & 8 & 15 & 8 & 15 & 8 & 80 & 40 & 24 & 200 \\
\hline & F31 & $1: 2$ & 30 & 15 & 30 & 15 & 30 & 15 & 30 & 15 & 20 & 10 & 19 & 200 \\
\hline & F32 & $1: 3$ & 45 & 15 & 45 & 15 & 45 & 15 & 45 & 15 & 60 & 20 & 17 & 300 \\
\hline
\end{tabular}

$$
\text { Friability }(\%)=\frac{(\text { Initial Weight-Final Weight })}{\text { Initial Weight }} \times 100
$$

Friability less than $1 \%$ is considered acceptable. Each batch was analysed thrice [26].

\section{Shape and area of pellets}

Shape and area of each pellet batch $(n \geq 50)$ was evaluated using stereomicroscope (Am Scope Digital, LED-1444A, USA). The digitalized images were further analysed by image analysis software (NIH Image J $1.47 \mathrm{v}$, USA). Area, perimeter, feret diameter were measured and shape factors were calculated as follows:

$$
d_{c e}=\sqrt{\frac{4 A}{\pi}}
$$

Aspect ratio $(A R)=d_{\max } / d_{\min }$

Circularity $(C)=4 \pi A / P^{2}$

Shape factor $\left(e_{R}\right)=\frac{2 \pi}{P} \frac{r_{e}}{f}-\sqrt{1-\left(\frac{b}{l}\right)^{2}}$ 


$$
\text { Correction factor }(f)=1.008-0.231\left(1-\frac{b}{l}\right)
$$

Where, $d_{c e}$ is the circle equivalent diameter, $A$ is the area, $d_{\text {min }}$ and $d_{\max }$ are the shortest and longest feret diameters respectively, $P$ is the perimeter, $e_{R}$ is the two dimensional shape factor, $r_{e}$ is the mean radius, $f$ is a correction factor, $l$ and $b$ are length and breadth of the pellet respectively. $b=l$ are round pellets, $b \quad l$ are elliptical pellets having an aspect ratio 1.2-1.5. The limiting value is 1.1 for aspect ratio, whereas, the acceptable lower limit value for $\mathrm{e}_{\mathrm{R}}$ is $0.6[27,28]$.

\section{Surface morphology and elemental characterization of pellets}

External morphology of pellets were visualized using Scanning electron microscope, SEM (JSM-6380A, Jeol, Japan) at $10 \mathrm{kV}$. Whole pellet was placed on aluminium studs and sputter coated with gold up to $250^{\circ} \mathrm{A}$ by means of an Auto Coater (JFC-1500, Jeol, Japan). Photomicrographs were obtained at magnification ranging from 50 to 1500 times. Elements were characterized using Energy Dispersive Spectrometer (EDS) attached with SEM at $20 \mathrm{kV}$ accelerated voltage.

\section{Drug content analysis}

Twenty capsules from each batch were randomly selected. The capsule contents were pulverized by means of mortar and pestle. $10 \mu \mathrm{g} / \mathrm{ml}$ sample solution was prepared by utilizing mean weight equivalent quantity in mobile phase containing $1.5 \mathrm{~g}$ of sodium 1heptanesulfonate in mixture of DW $(300 \mathrm{ml})$ and acetonitrile $(700 \mathrm{ml})$ at $\mathrm{pH} 4$ (adjusted with $0.1 \mathrm{~N}$ Sulfuric acid). The samples were sonicated, filtered and then injected. Signals were detected at $230 \mathrm{~nm}$. Assay was carried out using C18 column $(25 \mathrm{~cm} \times 4.6 \mathrm{~mm})$ with $5 \mu \mathrm{m}$ packing on HPLC (LC-10AT VP, No.C20973806986 LP, Shimadzu Corporation, Kyoto, Japan). Mean and standard deviation of three readings from each batch were used [25].

\section{In vitro drug release study}

Meclizine $\mathrm{HCl}$ release was determined using USP Apparatus 1 six station (Erweka DT600, Husenstamm, Germany) in $0.01 \mathrm{~N} \mathrm{HCl}(900 \mathrm{ml})$ maintained at $37 \pm 0.5{ }^{\circ} \mathrm{C}$ at $100 \mathrm{rpm} .10 \mathrm{ml}$ dissolution samples were drawn at each $1 \mathrm{~h}$ interval over $12 \mathrm{~h}$. Sink condition was maintained by immediately replenished volumes with fresh medium. Collected samples were filtered and finally diluted to attain suitable concentration. Samples were analysed at $230 \mathrm{~nm}$ on spectrophotometer (UV-1800, Double beam Spectrophotometer, No.A11454500172CD, Shimadzu Corporation, Kyoto, Japan). Cumulative drug release (percentage) was determined and plotted against time (hours). Six samples (mean of each batch) were used [29].

\section{Drug release kinetic studies \\ Model-dependent methods}

Various kinetic models including Zero-order (Eq. (13)), First-order (Eq. (14)), Higuchi square root (Eq. (15)), Hixson-Crowell cube root (Eq. (16)), Baker-Lonsdale (Eq. (17)), Jander's equation (Eq. (18)) and KorsmeyerPeppas model (Eq. (19)) were applied to in vitro release data of Meclizine $\mathrm{HCl}$ to determine its release kinetics using MS Excel (DD Solver).

$$
\begin{aligned}
& Q_{t}=k_{0} t \\
& \log Q_{t}=\log Q_{0}+k_{1} \frac{t}{2.303} \\
& Q_{t}=k_{H} t^{1 / 2} \\
& \sqrt[3]{Q_{0}}-\sqrt[3]{Q_{t}}=k_{H C} t \\
& 3 / 2\left[1-\left(1-M_{t} / M_{\infty}\right)^{2 / 3}\right]-{ }^{M_{t}} / M_{\infty}=k_{B L} t \\
& 1-\left(1-M_{t} / M_{\infty}\right)^{1 / 3}=k_{J} t^{1 / 2} \\
& M_{t} / M_{\infty}=k t^{n}
\end{aligned}
$$

where $Q_{t}$ is the amount of drug released in time $t, Q_{o}$ is the initial amount of drug in the sample, $M_{t}$. is the amount of drug released in time $t, M_{\infty}$ is the amount at infinite time, $M_{t .} / M_{\infty}$ is the fractional solute release, $t$ is the time in $\mathrm{h}, t_{1 / 2}$ is the square root of time and $K_{0}, K_{1}$, $K_{H}, K_{H O}, K_{B L}, K_{J}$ and $K$ are the release rate constants for Zero-order, First-order, Higuchi, Hixson-Crowell cube root, Baker-Lonsdale, Jander's equation and KorsmeyerPeppas model respectively. $n$ is an exponent which characterizes the different release mechanisms and calculated through slope of the straight line [30].

Drug release was further characterized by determining the mean dissolution time (MDT) and dissolution efficiency (DE) using following equations:

$$
\begin{gathered}
M D T=\frac{\sum_{j=1}^{n} \hat{t}_{j} \Delta M_{j}}{\sum_{j=1}^{n} \Delta M_{j}} \\
D . E=\frac{\int_{0}^{t} y \times d t}{y_{100} \times t} \times 100
\end{gathered}
$$

Where $j$ is the sample number, $n$ is the number of dissolution sample times, $t_{j}$ is the time at midpoint between $t_{j}$ and $t_{j-1}, \Delta \mathrm{M}_{\mathrm{j}}$ is the additional amount of drug dissolved between $t_{j}$ and $t_{j-1}$ and $y$ is the drug dissolved (percentage) at time $t[31]$. 
Model-independent method (dissolution profile comparison) Similarity in dissolution profiles was compared by determining the Similarity factor $\left(f_{2}\right)$ :

$$
f_{2}=50 \times \log \left\{\left[1+\left(\frac{1}{n}\right) \sum_{t-1}^{n}\left(R_{t}-T_{t}\right)^{2}\right]^{-0.5} \times 100\right\}
$$

Where $R_{t}$ and $T_{t}$ are the amount of drug released from the reference and test formulations at each time point, respectively, $n$ is the number of dissolution samples. Release profiles are considered different if $f_{2}<50$ [30].

\section{Stability studies}

Optimized ER pellets were studied at $40 \pm 2{ }^{\circ} \mathrm{C} /$ $75 \% \pm 5 \% \mathrm{RH}$ (relative humidity) for accelerated stability for 6 months, in line with guidelines of International Conference on Harmonisation (ICH). Encapsulated pellets were placed in amber glass bottles and stored in humidity chamber (Nuaire, USA). Samples were drawn every 3 months and their drug content, physical appearance and release characteristics in different media were determined. Software Stab (R-Gui, version 3.1.1) was used to calculate the shelf life.

\section{Results}

\section{Influence of lipids}

Initial trial formulations in Group 1 were prepared using single lipid in order to evaluate its effect on drug release and sphericity. Three formulations were prepared with each lipid in drug/lipid ratio of 1:0.5-1:2 as shown in Table 1. Although, MCC serves as an extrusion aid in concentrations less than $20 \%$, but in this study amount of MCC was kept constant at $40 \%$ in order to prolong the release of poorly soluble $\mathrm{Meclizine} \mathrm{HCl}$.

\section{Effect of Geleol (GMS)}

Large and highly spherical pellets (Table 1) were prepared by using Geleol (GMS) which utilized 30-39\% granulating fluid, illustrated in Fig. 1(a). Highest aspect ratio (1.005) and shape factor (0.997) were obtained in Geleol pellets in drug/lipid ratio of 1:2. Amount of granulating fluid was decreased with increased drug/ lipid ratio (Table 1). Release of Meclizine $\mathrm{HCl}$ was rapid from Geleol pellets (F1-F3), shown in Fig. 2(a).

\section{Effect of Precirol (GPS)}

Small and nearly spherical pellets (Table 1), were formulated by using Precirol (GPS) which required, 33-44\% granulating fluid, shown in Fig. 1(b). Aspect ratio and shape factor of Precirol pellets ranged from 1.027-1.047 and $0.611-0.743$ respectively. Meclizine $\mathrm{HCl}$ was rapidly released from Precirol pellets (F4-F6). Precirol pellets having drug/lipid ratio 1:2, illustrated in Fig. 2(a) released $90 \%$ drug within 2 hours.

\section{Effect of Compritol' (GB)}

F7-F9 comprised of Compritol pellets which utilized $33-43 \%$ granulating fluid during preparation of pellets. Pellets were large and almost spherical having aspect ratio (1.017-1.058) and two dimensional shape factor (0.665-0.729), shown in Fig. 1(c). Release of Meclizine $\mathrm{HCl}$ was decreased as the concentration of Compritol was increased, illustrated in Fig. 2(a).

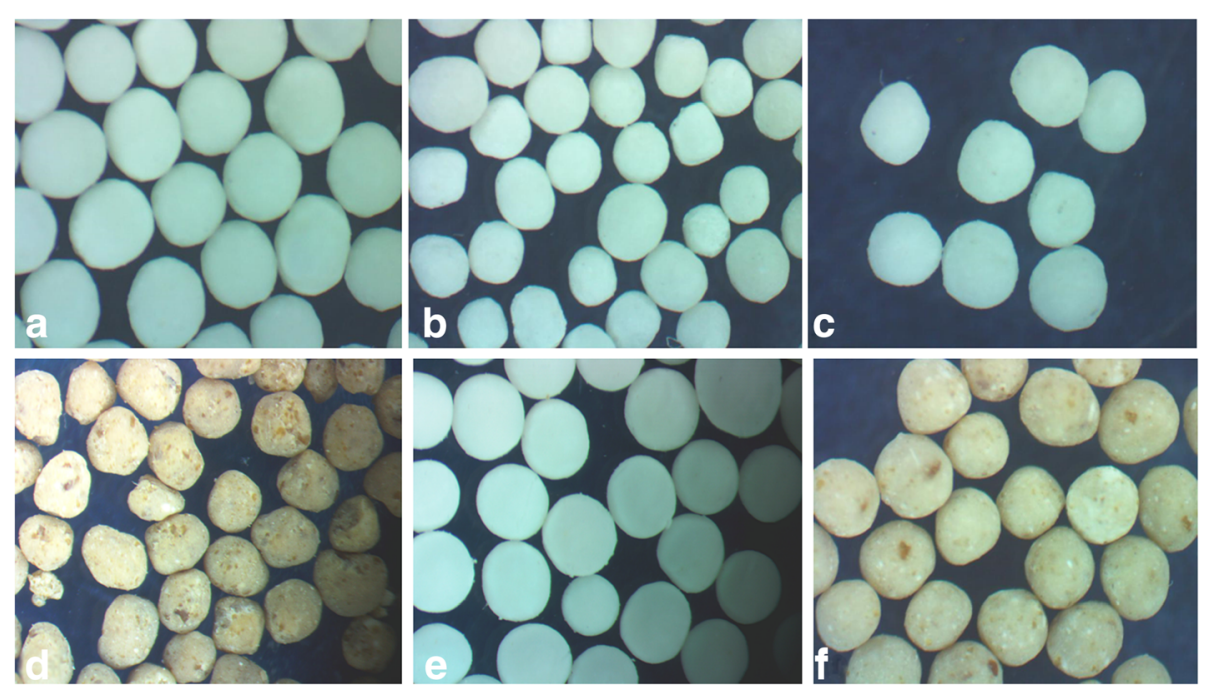

Fig. 1 Stereo images of Meclizine $\mathrm{HCl}$ matrix pellets prepared with (a) Geleol ${ }^{\circ}$ (b) Precirol ${ }^{\circ}$ (c) Compritol $\left.\right|^{\circ}$ (d) CW (e) Geleol $\left.\right|^{\circ}$ and Compritol ${ }^{\circ}$ (f) Geleol', Compritol and CW 


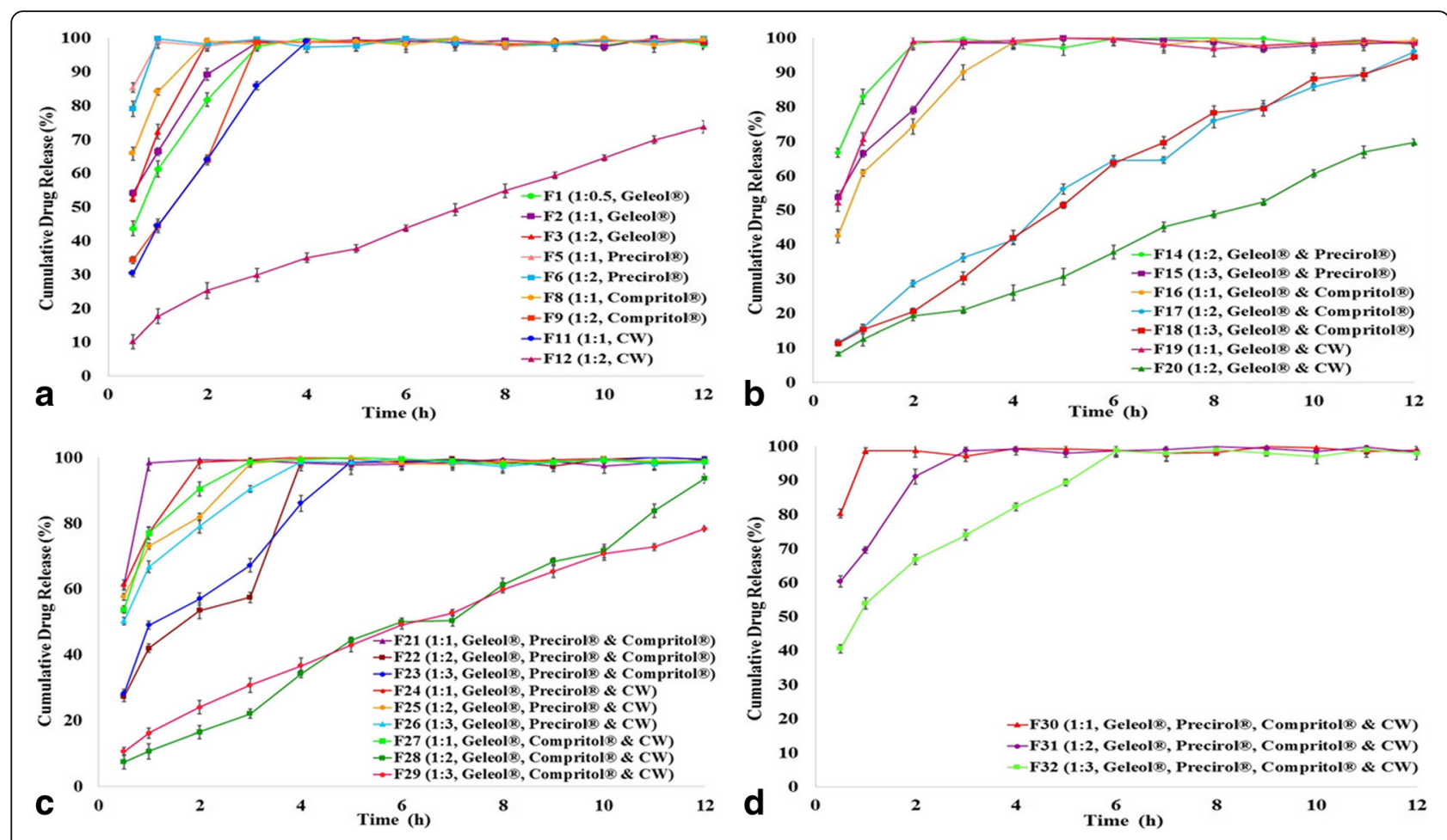

Fig. 2 In vitro release profiles of Meclizine $\mathrm{HCl}$ matrix pellets showing effect of (a) single lipid (b) combinations of two lipids (c) combinations of three lipids (d) combinations of four lipids

\section{Effect of carnauba wax}

CW formed large and irregularly shaped pellets, even in presence of $40 \%$ MCC, shown in Fig. 1(d). Lowest aspect ratio (1.309) and shape factor (0.499) were obtained in $\mathrm{CW}$ pellets. As concentration of $\mathrm{CW}$ was increased in the matrix pellets, aspect ratio was also increased but shape factor was decreased. Release of Meclizine $\mathrm{HCl}$ from CW pellets showed inverse relationship (F10-F12). F12 released only $73 \%$ drug over a period of $12 \mathrm{~h}$, illustrated in Fig. 2(a).

\section{Effect of MCC}

MCC formed spherical pellets of Meclizine $\mathrm{HCl}$ with Geleol', Precirol $^{\circ}$ and Compritol. When it was used with CW irregularly shaped pellets were formed, shown in Fig. 1(d). This irregularity in shape was more pronounced with increased concentration of CW. MCC (40\%) had no effect on release of Meclizine $\mathrm{HCl}$.

\section{Effect of combinations of two lipids}

Results of Group 1 indicated that Geleol formed highly spherical pellets, compared to other lipids. Therefore, Geleol was added in each formulation of Group 2 by replacing some amount of MCC to produce round pellets. Group 2 combinations, (i). Geleol and Compritol and (ii) Geleol and CW produced retarding effect on drug release. Geleol and Compritol formed highly spherical and round pellets, shown in Fig. 1(e). Release of Meclizine $\mathrm{HCl}$ was successfully sustained by combination of $\mathrm{Geleol}^{\circ}$ and Compritol at drug/lipid ratio of 1:2 (F17) and 1:3 (F18). F17 and F18 released 90\% drug within 11 and $12 \mathrm{~h}$ respectively, shown in Fig. 2(b). Combination of Geleol and CW at drug/lipid ratio of 1:1 (F19) and 1:2 (F20) also produced spherical shaped pellets. F19 (1:1) released 90\% drug within 2 h. F20 (1:2) released 69\% drug which indicated a pronounced retardation in drug release, shown in Fig. 2(b).

\section{Effect of combinations of three lipids}

In Group 3, Geleol and two other lipids were combined to evaluate cumulative influence on drug release and sphericity. Group 3 pellets were spherical (Fig. 1(f)) with acceptable aspect ratios and shape factors (Table 2). In Group 3, the combination of Geleol, Compritol and CW in drug/ lipid ratio of 1:2 (F28) and 1:3 (F29), effectively prolonged the drug release up to $12 \mathrm{~h}$. Combination of Geleol, Compritol and CW in drug/lipid ratio of 1:3 (F29) released $78 \%$ drug at the end of $12 \mathrm{~h}$, indicating excessive control on release of Meclizine $\mathrm{HCl}$, shown in Fig. 2(c).

\section{Effect of combinations of four lipids}

In Group 4, all four lipids were combined (F30-F32) to determine effects on drug release and sphericity. The combination of four lipids resulted in formation of 
Table 2 Image analysis of Meclizine HCl ER matrix pellets formulations

\begin{tabular}{|c|c|c|c|c|c|c|c|}
\hline Codes & Area & Perimeter & Circularity & Feret diameter $(\mu \mathrm{m})$ & dce & Aspect Ratio & $e R$ \\
\hline$\overline{F 1}$ & 10,900 & 390.771 & 0.897 & 121.696 & 117.836 & 1.016 & 0.970 \\
\hline $\mathrm{F} 2$ & 12,522 & 411.942 & 0.927 & 133.765 & 126.300 & 1.052 & 0.891 \\
\hline F3 & 14,304 & 438.502 & 0.935 & 140.357 & 134.988 & 1.005 & 0.997 \\
\hline $\mathrm{F} 4$ & 8729 & 360.185 & 0.846 & 111.879 & 105.450 & 1.047 & 0.611 \\
\hline F5 & 8801 & 355.000 & 0.878 & 110.725 & 105.884 & 1.027 & 0.743 \\
\hline F6 & 10,349 & 376.124 & 0.919 & 119.641 & 114.819 & 1.043 & 0.712 \\
\hline F7 & 10,044 & 383.563 & 0.858 & 119.436 & 113.115 & 1.017 & 0.665 \\
\hline F8 & 10,424 & 377.838 & 0.918 & 121.840 & 115.234 & 1.058 & 0.700 \\
\hline F9 & 12,868 & 417.443 & 0.928 & 133.544 & 128.033 & 1.042 & 0.729 \\
\hline F10 & 13,464 & 438.623 & 0.879 & 143.171 & 130.964 & 1.153 & 0.551 \\
\hline F11 & 13,513 & 431.267 & 0.913 & 150.881 & 131.202 & 1.234 & 0.548 \\
\hline F12 & 14,422 & 444.383 & 0.918 & 155.003 & 135.543 & 1.309 & 0.499 \\
\hline F13 & 10,773 & 384.07 & 0.918 & 125.543 & 117.148 & 1.073 & 0.675 \\
\hline F14 & 11,553 & 393.681 & 0.937 & 130.648 & 121.314 & 1.093 & 0.675 \\
\hline F15 & 12,366 & 411.898 & 0.916 & 136.015 & 125.510 & 1.069 & 0.854 \\
\hline F16 & 12,143 & 405.315 & 0.929 & 133.989 & 124.374 & 1.068 & 0.735 \\
\hline F17 & 12,758 & 415.931 & 0.927 & 133.417 & 127.484 & 1.092 & 0.750 \\
\hline F18 & 14,773 & 461.71 & 0.871 & 143.809 & 137.183 & 1.050 & 0.970 \\
\hline F19 & 11,504 & 395.95 & 0.922 & 125.873 & 121.057 & 1.031 & 0.718 \\
\hline F20 & 12,573 & 412.134 & 0.93 & 139.119 & 126.557 & 1.083 & 0.840 \\
\hline F21 & 12,830 & 432.91 & 0.86 & 134.358 & 127.843 & 1.055 & 0.758 \\
\hline$F 22$ & 14,213 & 437.057 & 0.935 & 141.209 & 134.558 & 1.028 & 0.773 \\
\hline F23 & 14,952 & 463.925 & 0.873 & 147.146 & 138.011 & 1.063 & 0.988 \\
\hline F24 & 10,819 & 395.937 & 0.867 & 124.808 & 117.397 & 1.066 & 0.801 \\
\hline F25 & 12,720 & 412.587 & 0.939 & 133.989 & 127.294 & 1.052 & 0.772 \\
\hline F26 & 13,067 & 419.126 & 0.935 & 133.135 & 129.0188 & 1.046 & 0.726 \\
\hline F27 & 12,477 & 409.367 & 0.936 & 132.412 & 126.0725 & 1.039 & 0.737 \\
\hline F28 & 13,576 & 427.222 & 0.935 & 138.004 & 131.5077 & 1.069 & 0.721 \\
\hline F29 & 14,992 & 448.414 & 0.937 & 144.7 & 138.1958 & 1.028 & 0.838 \\
\hline F30 & 11,517 & 404.16 & 0.886 & 130.973 & 121.1253 & 1.098 & 0.796 \\
\hline F31 & 11,343 & 397.655 & 0.901 & 125.196 & 120.2068 & 1.007 & 0.768 \\
\hline F32 & 12,884 & 418.726 & 0.923 & 134.302 & 128.1122 & 1.041 & 0.882 \\
\hline
\end{tabular}

spherical pellets (Table 2) with rapid drug release, illustrated in Fig. 2(d).

\section{Drug excipient interactions}

Characteristic peaks of pure drug at $2986.61 \mathrm{~cm}^{-1}$ (C-H str.), $1658.57 \mathrm{~cm}^{-1}\left(\mathrm{C}=\mathrm{C}\right.$ str.), $1499.21 \mathrm{~cm}^{-1}$ (CH2 bending), $1433.83 \mathrm{~cm}^{-1}$ (CH3), $1270.37 \mathrm{~cm}^{-1}$ (C-N str.), $718.78 \mathrm{~cm}^{-1}$ (C-Cl str.) are illustrated in Fig. 3(a). FTIR spectra of optimized formulations of F17 (Combination of Geleol and Compritol'), F20 (Combination of Geleol and CW) and F28 (Combination of $\mathrm{Geleol}^{\circ}$, Compritol and $\mathrm{CW}$ ) are shown in
Fig. 3(b), (c) \& (d) respectively, indicating absence of any drug lipid interactions.

\section{Flow properties and friability of pellets}

Table 3 shows rheological properties of formulations. Results of compressibility index, hausner ratio and angle of repose indicate excellent flow properties for all lipids (Geleol', Precirol and Compritol ${ }^{\circ}$ ) of Group 1 except CW. Combination of CW with other lipids in Group 2, Group 3 and Group 4 resulted in pellets with satisfactory flow properties. Friability of all pellet formulations was adequate, indicating that pellets were strong enough 

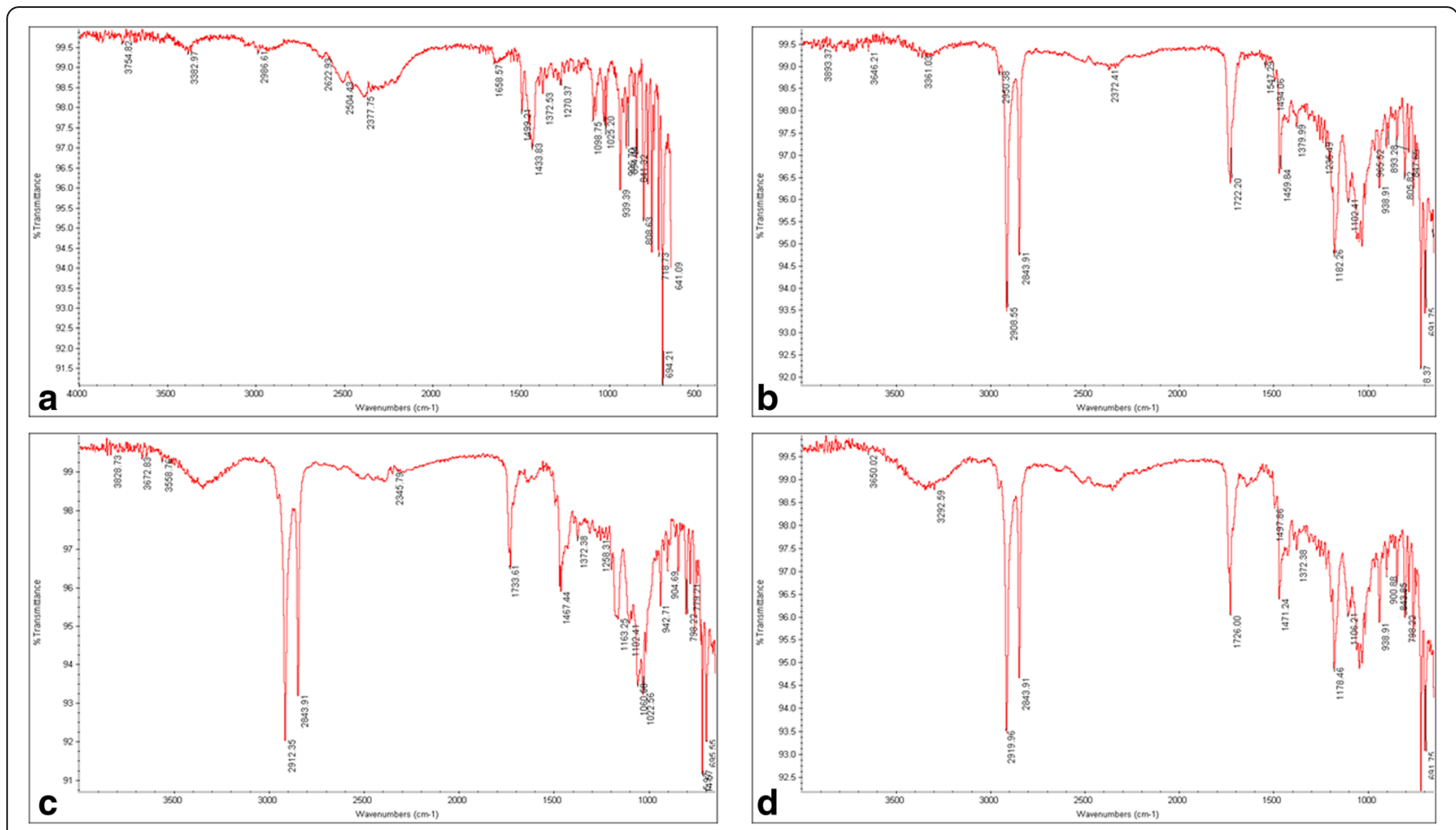

Fig. 3 FTIR spectra showing (a) pure Meclizine $\mathrm{HCl}$ (b) combination of Geleo ${ }^{\oplus}$ and Compritol in drug/lipid ratio of 1:2 (F17) (c) combination of Geleol and CW in drug/lipid ratio of 1:2 (F20) (d) combination of Geleol', Compritol and CW in drug/lipid ratio of 1:2 (F28)

to bear attrition and shock during transportation, consumption and storage.

\section{Assay and moisture content of Meclizine $\mathrm{HCl}$ pellets}

The content (percent) of Meclizine $\mathrm{HCl}$ in each pellet formulation was within the label claim (60 mg/capsule) as shown in Table 3. MC of all formulations was decreased with the increase in concentration of lipids (Table 3). Among all four lipids, the least MC was observed in CW pellets whereas the highest MC was noted in Precirol pellets.

\section{Effect of dissolution medium $\mathrm{pH}$ on drug release}

Fig. 4(a), (b) \& (c) show dissolution profiles of Meclizine $\mathrm{HCl}$ pellets at $\mathrm{pH} 1.2(\mathrm{HCl}), 4.5$ and 6.8 (phosphate buffer) respectively. Meclizine $\mathrm{HCl}$ release was decreased as $\mathrm{pH}$ increased from 1.2 to 6.8 .

\section{Drug release kinetics}

\section{Model-dependent methods}

Table 4 shows release kinetic data of all formulations. On the basis of best goodness of fit, the most appropriate model was selected. Optimized formulations containing combination of Geleol and Compritol at drug/ lipid ratio of 1:2 (F17) and 1:3 (F18) showed highest linearity when applied to Korsmeyer-Peppas equation $\left(\mathrm{R}^{2}=0.978-0.993\right)$. These formulations exhibited nonFickian diffusion (anomalous transport), indicating that
Meclizine $\mathrm{HCl}$ release was controlled by both diffusion and erosion.

Combination of CW either with Geleol (F20) or Geleol $^{\circ}$ and Compritol (F28 and F29) displayed best fit in Zero-order $\left(\mathrm{R}^{2}=0.991-0.995\right)$ indicating concentration independent Meclizine $\mathrm{HCl}$ release. The release constants $(k)$ were higher for increased drug mass fraction and lower for increased lipid concentration. Concerning the influence of lipid type, lower release constants were found in $\mathrm{CW}$ pellets.

MDT was directly related to physicochemical properties of drug as well as the concentration and nature of lipids [19]. MDT was increased with increased concentration of lipids. This effect was more pronounced in combinations of Geleol and CW (F20) and Geleol, Compritol and CW (F28). The highest $\mathrm{DE}_{6}$ was observed in combination of Geleol and Compritol (F17).

\section{Model-independent method}

Out of thirty two formulations, five formulations F17 (Geleol ${ }^{\circ}$ and Compritol $^{\circ}, 1: 2$ ), F18 (Geleol ${ }^{\circ}$ and Compritol $^{\circ}$ 1:3), F20 (Geleol and CW, 1:2), F28 (Geleol, Compritol and CW, 1:2) and F29 (Geleol, Compritol $^{\circ}$ and $C W, 1: 3)$ showed extended drug release up to $12 \mathrm{~h}$. Combination of Geleol $^{\circ}$ and Compritol in drug/lipid ratio of 1:2 (F17) was selected as a reference formulation because of high sphericity of pellets with smooth surface and controlled release profile. Although, similar 
Table 3 Physicochemical characteristics of Meclizine $\mathrm{HCl}$ ER matrix pellets formulations

\begin{tabular}{|c|c|c|c|c|c|c|c|c|c|}
\hline $\begin{array}{l}\text { Formulation } \\
\text { Code }\end{array}$ & $\begin{array}{l}\text { Angle of Repose } \\
\theta\end{array}$ & $\begin{array}{l}\text { Bulk Density } \\
\mathrm{g} / \mathrm{ml}\end{array}$ & $\begin{array}{l}\text { Tapped Density } \\
\mathrm{g} / \mathrm{ml}\end{array}$ & $\begin{array}{l}\text { Compressibility Index } \\
\%\end{array}$ & $\begin{array}{l}\text { Hausner } \\
\text { Ratio }\end{array}$ & $\begin{array}{l}\text { Moisture Content } \\
\%\end{array}$ & $\begin{array}{l}\text { Yield } \\
\%\end{array}$ & $\begin{array}{l}\text { Friability } \\
\%\end{array}$ & $\begin{array}{l}\text { Assay } \\
\%\end{array}$ \\
\hline$\overline{F 1}$ & 21.324 & 0.666 & 0.714 & 6.723 & 1.072 & 18.591 & 88.641 & 0.523 & 96.163 \\
\hline F2 & 21.697 & 0.689 & 0.741 & 6.992 & 1.075 & 15.143 & 84.971 & 0.608 & 99.741 \\
\hline F3 & 20.582 & 0.652 & 0.704 & 7.386 & 1.080 & 9.947 & 74.698 & 0.589 & 97.957 \\
\hline F4 & 25.639 & 0.747 & 0.807 & 7.435 & 1.080 & 25.667 & 79.614 & 0.399 & 96.745 \\
\hline F5 & 24.714 & 0.752 & 0.821 & 8.404 & 1.092 & 31.357 & 74.018 & 0.408 & 98.237 \\
\hline F6 & 25.916 & 0.789 & 0.859 & 8.149 & 1.089 & 35.987 & 69.943 & 0.418 & 100.024 \\
\hline F7 & 25.146 & 0.799 & 0.876 & 8.790 & 1.096 & 21.228 & 85.472 & 0.476 & 99.242 \\
\hline F8 & 26.357 & 0.765 & 0.832 & 8.053 & 1.088 & 18.298 & 84.608 & 0.287 & 97.589 \\
\hline F9 & 28.699 & 0.760 & 0.834 & 8.873 & 1.097 & 13.952 & 90.947 & 0.591 & 98.241 \\
\hline F10 & 37.473 & 0.839 & 0.999 & 16.016 & 1.191 & 13.694 & 88.364 & 0.340 & 99.415 \\
\hline F11 & 38.258 & 0.801 & 0.989 & 19.009 & 1.235 & 11.037 & 91.348 & 0.379 & 99.876 \\
\hline F12 & 40.981 & 0.779 & 0.975 & 20.103 & 1.252 & 9.024 & 94.289 & 0.251 & 98.279 \\
\hline F13 & 25.007 & 0.671 & 0.710 & 5.493 & 1.058 & 29.195 & 76.617 & 0.308 & 99.873 \\
\hline F14 & 27.242 & 0.606 & 0.648 & 6.481 & 1.069 & 24.834 & 81.753 & 0.291 & 100.390 \\
\hline F15 & 26.321 & 0.669 & 0.719 & 6.954 & 1.075 & 19.479 & 85.439 & 0.258 & 99.220 \\
\hline F16 & 25.364 & 0.769 & 0.831 & 7.461 & 1.081 & 5.870 & 92.760 & 0.578 & 97.289 \\
\hline F17 & 26.821 & 0.785 & 0.861 & 8.827 & 1.097 & 3.930 & 96.219 & 0.530 & 99.657 \\
\hline F18 & 28.974 & 0.815 & 0.906 & 10.044 & 1.112 & 2.966 & 97.124 & 0.599 & 98.917 \\
\hline F19 & 32.147 & 0.826 & 0.931 & 11.278 & 1.127 & 5.942 & 94.283 & 0.276 & 99.814 \\
\hline F20 & 34.917 & 0.839 & 0.964 & 12.967 & 1.149 & 2.456 & 97.068 & 0.342 & 97.668 \\
\hline F21 & 25.231 & 0.654 & 0.713 & 8.275 & 1.090 & 27.894 & 87.925 & 0.562 & 98.749 \\
\hline F22 & 27.951 & 0.678 & 0.730 & 7.123 & 1.077 & 24.276 & 91.478 & 0.431 & 98.529 \\
\hline F23 & 28.367 & 0.651 & 0.710 & 8.310 & 1.091 & 19.875 & 83.879 & 0.539 & 99.384 \\
\hline F24 & 34.852 & 0.775 & 0.891 & 13.019 & 1.150 & 21.763 & 86.168 & 0.487 & 99.876 \\
\hline F25 & 32.753 & 0.801 & 0.939 & 14.696 & 1.172 & 18.258 & 87.309 & 0.509 & 98.254 \\
\hline F26 & 34.258 & 0.794 & 0.939 & 15.442 & 1.183 & 15.734 & 90.951 & 0.417 & 97.413 \\
\hline$F 27$ & 31.159 & 0.701 & 0.798 & 12.155 & 1.138 & 26.013 & 79.571 & 0.378 & 99.643 \\
\hline F28 & 31.984 & 0.755 & 0.879 & 14.107 & 1.164 & 9.876 & 96.527 & 0.314 & 98.872 \\
\hline F29 & 32.679 & 0.721 & 0.848 & 14.976 & 1.176 & 10.325 & 94.994 & 0.291 & 100.954 \\
\hline F30 & 32.774 & 0.745 & 0.852 & 12.559 & 1.144 & 7.410 & 90.890 & 0.451 & 98.371 \\
\hline F31 & 33.891 & 0.762 & 0.885 & 13.898 & 1.161 & 4.337 & 95.840 & 0.514 & 100.547 \\
\hline F32 & 33.694 & 0.800 & 0.937 & 14.621 & 1.171 & 4.230 & 88.197 & 0.479 & 99.875 \\
\hline
\end{tabular}

properties were obtained in combination of Geleol and Compritol pellets in drug/lipid ratio of 1:3 (F18), but higher quantity of Compritol was used in F18 as compared to F17. Dissolution profile of F18 was only similar with F17 having $f_{2}$ value 71.604 .

\section{Scanning electron microscopy (SEM)}

Surface morphology of pellets was revealed by SEM. Combinations of Geleol and Compritol F17 and F18 exhibited smooth surface and appeared spherical and intact in shape, shown in Fig. 5(a) \& (b) respectively. Geleol and $\mathrm{Compritol}^{\circ}$ pellets in drug/lipid ratio of 1:2
(F17), was compared with drug/lipid ratio of 1:3 (F18), for external morphology and texture. These (Fig. 5(a) \& (b)) show that both pellet formulations were almost similar in appearance. SEM images indicated that external morphology was independent of drug/lipid ratio. Significant difference in cross section of drug/lipid ratio of 1:2 (F17) and 1:3 (F18) was observed. Figure 5(d) shows that F18 (1:3) had dense network of lipid matrix, as compared to F17 (1:2), shown in Fig. 5(c). SEM images of Geleol and CW (F20) displayed irregularly shaped pellets with highly rough surface and hollow depressions, shown in Fig. 6(a). These irregularly shaped 

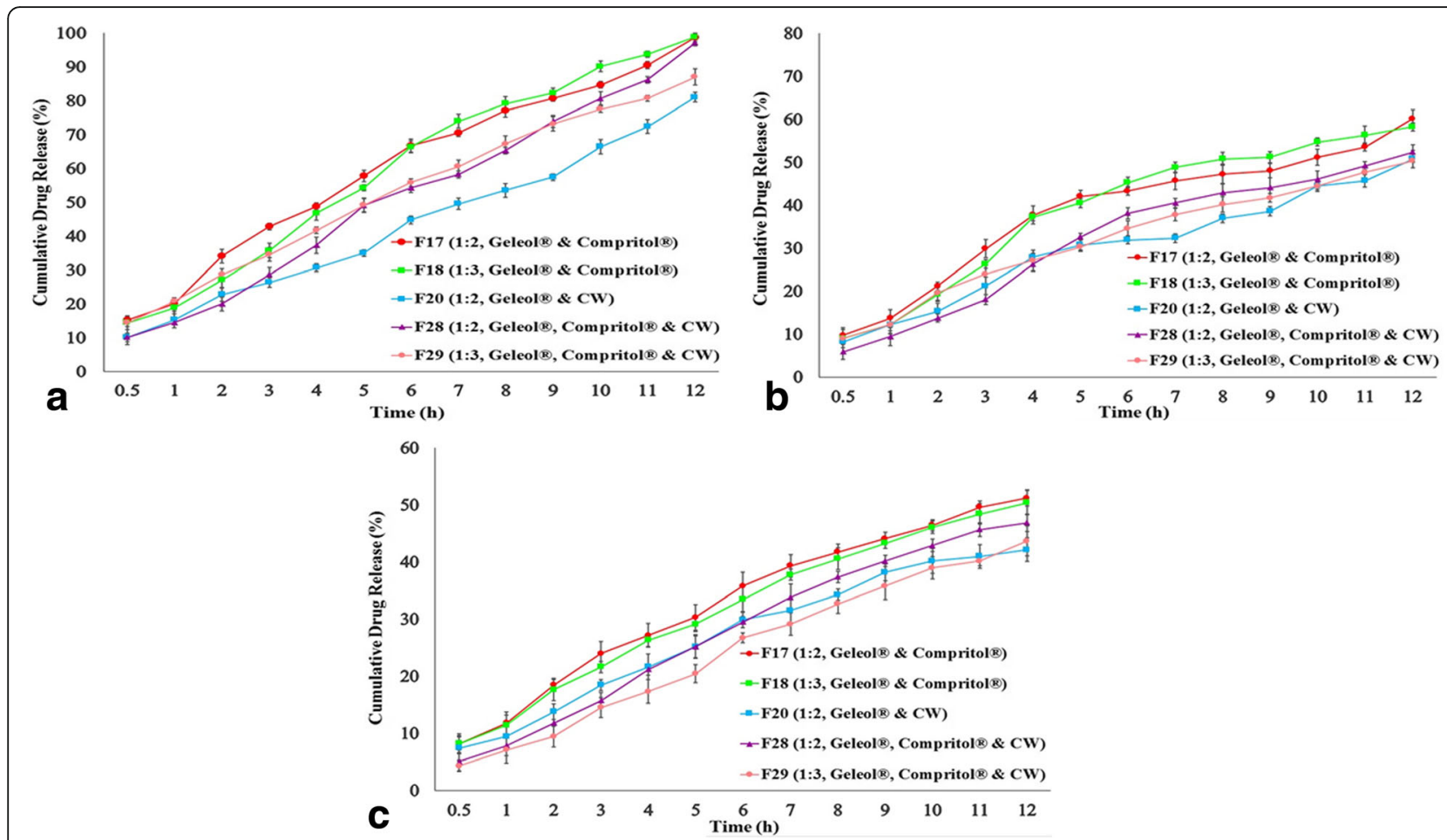

Fig. 4 In vitro release profiles showing combinations of Geleol ${ }^{\circ}$ and Compritol ${ }^{\circ}$ in drug/lipid ratio of 1:2 (F17), 1:3 (F18), combination of Geleol ${ }^{\circ}$ and CW in drug/lipid ratio of 1:2 (F20) and combination of Geleol ${ }^{\circ}$, Compritol ${ }^{\circ}$ and CW in drug/lipid ratio of 1:2 (F28), and 1:3 (F29) at (a) pH 1.2 (b) $\mathrm{pH} 4.5$ (c) $\mathrm{pH} 6.8$

pellets were made almost spherical by the addition of Com-

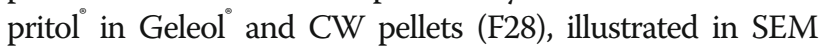
image Fig. 6(b). It showed rough surface with less depressions and were nearly spherical in shape. Figure $6 c$ \& d show cross section of F20 and F28 respectively.

\section{Energy dispersive spectroscopy (EDS)}

Elements carbon, oxygen and chlorine were found in combination of Geleol and Compritol pellets (F17) as shown in Fig. 7(a). The highest content of carbon was due to the organic drug containing carbon chain. Combination of Geleol, Compritol and CW (F28) showed additional peaks of aluminum, copper and zinc (Fig. 7(b)) due to presence of CW in addition to Compritol $^{\circ}$ and Geleol.

\section{Stability}

Optimized formulations of lipids showed acceptable stability for 6 months at $40{ }^{\circ} \mathrm{C} \pm 2{ }^{\circ} \mathrm{C} / 75 \% \pm 5 \% \mathrm{RH}$. No significant difference in physical appearance, in vitro drug release and drug content was observed except in the combination of Geleol and CW (F20). This lipid combination released only $66 \%$ drug at the end of $12 \mathrm{~h}$ after storage of 6 months. Results indicated shelf-life of 37 months with $90 \%$ lower acceptance limit of label claim.

\section{Discussion}

Extended release pellets of poorly soluble antiemetic agent Meclizine $\mathrm{HCl}$ were prepared by extrusion spheronization method using Geleol, Precirol, Compritol $^{\circ}$ and CW. Highly spherical pellets with faster drug release were prepared using Geleol. These pellets were rapidly hydrated in dissolution medium due to presence of two free hydroxyl groups in their structure and a higher HLB value (3.8), as higher HLB values are associated with increased drug release rate [32]. Similar surface active property of GMS was observed by Quadir et al. [22]. It is also reported that addition of GMS in pellet formulations resulted in higher drug release rate due to formation of pores [11]. Wadher et al., formulated GMS based SR tablets of Metformin $\mathrm{HCl}$ in $\mathrm{drug} /$ wax ratio of 1:0.6 which released 95\% drug at the end of $12 \mathrm{~h}$ [33]. Cheboyina and Wyandt reported that GMS pellets reduced drug release rate depending on drug solubility [10].

ER Meclizine $\mathrm{HCl}$ pellets with Precirol showed rapid drug release. Pellet size was influenced by the physical properties of the blend constituents, drug/lipid ratio, type and quantity of granulating fluid. It was observed that Precirol $^{\circ}$ used in drug/lipid ratio of 1:3 (60\%) resulted in complete drug released within 2 hours. It was previously reported that Precirol was unable to 
Table 4 Kinetic parameters for dissolution data of different Meclizine $\mathrm{HCl}$ ER matrix pellets formulations according to various kinetic models

\begin{tabular}{|c|c|c|c|c|c|c|c|c|c|c|c|c|c|c|c|c|c|}
\hline \multirow[t]{2}{*}{ Codes } & \multicolumn{2}{|c|}{ Zero order } & \multicolumn{2}{|c|}{ First order } & \multicolumn{2}{|c|}{ Higuchi model } & \multicolumn{2}{|c|}{ Hixson-Crowell model } & \multicolumn{2}{|c|}{$\begin{array}{l}\text { Baker and } \\
\text { Lonsdale } \\
\text { model }\end{array}$} & \multicolumn{2}{|c|}{$\begin{array}{l}\text { Jander's } \\
\text { equation } \\
\text { model }\end{array}$} & \multicolumn{3}{|c|}{$\begin{array}{l}\text { Korsmeyer-Peppas } \\
\text { model }\end{array}$} & \multirow{2}{*}{$\begin{array}{l}\text { MDT } \\
\mathrm{h}\end{array}$} & \multirow{2}{*}{$\begin{array}{l}\mathrm{DE}_{6} \\
\%\end{array}$} \\
\hline & $\mathrm{R} 2$ & $\begin{array}{l}\mathrm{K} 0 \\
(\mathrm{~h}-1) \\
\end{array}$ & R2 & $\begin{array}{l}\mathrm{K} 1 \\
(\mathrm{~h}-1)\end{array}$ & R2 & $\begin{array}{l}\mathrm{KH} \\
(\mathrm{h}-1 / 2)\end{array}$ & R2 & $\begin{array}{l}\mathrm{KHC} \\
(\mathrm{h}-1) \\
\end{array}$ & R2 & $\begin{array}{l}\mathrm{KBL} \\
(\mathrm{h}-1)\end{array}$ & R2 & $\begin{array}{l}\mathrm{KJ} \\
(\mathrm{h}-1 / 2)\end{array}$ & $\mathrm{R} 2$ & $\begin{array}{l}\text { KKP } \\
(h-n)\end{array}$ & $n$ & & \\
\hline $\mathrm{F} 1$ & 0.917 & 16.152 & 0.937 & 1.992 & 0.972 & 45.274 & 977 & 1.142 & 0.974 & 0.197 & 0.925 & 0.504 & 0.986 & 0.507 & 90 & 1.724 & N/A \\
\hline$=2$ & 0.964 & 18.114 & 0.954 & 0.225 & 0.990 & 45.081 & 0.995 & 1.012 & 0.993 & 0.165 & 0.966 & 0.771 & 0.993 & 0.620 & 0.425 & 0.819 & N/A \\
\hline 3 & 0.987 & 29.600 & 0.961 & 3.243 & 1.000 & 64.028 & 0.988 & 1.756 & 0.983 & 0.256 & 0.961 & 1.028 & 1.000 & 0.724 & 0.451 & 0.687 & N/A \\
\hline F8 & 0.998 & 25.444 & 0.954 & 2.204 & 0.983 & 54.270 & 0.973 & 1.353 & 0.966 & 0.250 & 0.935 & 0.840 & 0.972 & 0.701 & 0.536 & 0.531 & N/A \\
\hline 9 & 0.991 & 12.015 & 0.809 & 1.515 & 0.973 & 40.471 & 0.92 & 0.461 & 0.866 & 0.116 & 0.830 & 0.608 & 0.985 & 0.323 & 0.575 & 1.343 & $\mathrm{~N} / \mathrm{A}$ \\
\hline F11 & 0.997 & 21.762 & 0.961 & 2.611 & 0.992 & 53.325 & 0.983 & 0.665 & 0.948 & 0.205 & 0.948 & 0.600 & 0.997 & 0.528 & 0.572 & 1.496 & N/A \\
\hline 12 & 0.992 & 5.237 & 0.981 & 0.136 & 0.982 & 22.473 & 0.99 & 0.124 & 0.939 & 0.016 & 0.944 & 0.222 & 0.991 & 0.185 & 0.556 & 4.884 & 29.676 \\
\hline$=14$ & 0.958 & 20.305 & 0.986 & 2.029 & 0.979 & 44.307 & 1.000 & 1.355 & 1.000 & 0.205 & 0.988 & 0.623 & 0.995 & 0.809 & 0.281 & 0.528 & N/A \\
\hline 15 & 0.988 & 17.162 & 0.852 & 1.342 & 0.980 & 41.982 & (9) & 0.948 & 111 & 0.139 & 0.861 & 0.48 & 0.978 & 0.692 & 23 & 0.921 & $\mathrm{~N} / \mathrm{A}$ \\
\hline 16 & 0.957 & 15.413 & 0.908 & 2.089 & 0.989 & 42.662 & 0.978 & 0.760 & 0.973 & 0.155 & 0.936 & 0.686 & 0.990 & 0.481 & 0.519 & 1.159 & NA \\
\hline 17 & 0.978 & 7.315 & 0.916 & 0.515 & 0.989 & 31.730 & 0.977 & 0.230 & 0.924 & 0.066 & 0.914 & 0.503 & 0.993 & 0.244 & 0.551 & 4.836 & 33.933 \\
\hline 18 & 0.974 & 7.697 & 0.957 & 0.404 & 0.979 & 33.287 & 0.989 & 0.235 & 0.947 & 0.041 & 0.930 & 0.416 & 0.978 & 0.215 & 0.597 & 4.832 & 33.698 \\
\hline 19 & 0.995 & 30.747 & 0.954 & 2.650 & 1.000 & 66.247 & 0.982 & 1.786 & 0.975 & 0.259 & 0.950 & 0.813 & 0.999 & 0.719 & 0.461 & 0.700 & NA \\
\hline 20 & 0.995 & 5.366 & 0.968 & 0.150 & 0.956 & i & 0. & 0. & 5 & 0.0 & 0. & 0.4 & 8 & 6 & 78 & 5.448 & 27.074 \\
\hline$=22$ & 0.887 & 17.594 & 0.663 & 3.561 & 0.841 & 46.653 & 0.740 & 0.748 & 0.682 & 0.356 & 0.654 & 1.950 & 0.905 & 0.472 & 0.533 & 1.921 & NA \\
\hline 23 & 0.967 & 14.414 & 0.796 & 2.389 & 0.966 & 42.713 & 0.907 & 0.606 & 0.872 & 0.195 & 0.832 & 1.20 & 0.963 & 2.389 & 0.501 & 1.855 & NA \\
\hline F24 & 0.990 & 24.496 & 0.966 & 2.309 & 1.000 & 52.932 & 0.990 & 1.546 & 0.987 & 0.230 & 0.963 & 0.706 & 1.000 & 0.777 & 0.345 & 0.604 & NA \\
\hline 25 & 0.960 & 14.995 & 0.874 & 1.205 & 0.971 & 37.046 & 0933 & 0.858 & 0.929 & 0.128 & 0.886 & 0.442 & 0.973 & 0.723 & 0.273 & 0.816 & NA \\
\hline F26 & 0.950 & 13.089 & 0.908 & 0.635 & 0.987 & 36.336 & 0.978 & 0.701 & 0.979 & 0.103 & 0.940 & 0.315 & 0.992 & 0.637 & 0.316 & 1.023 & NA \\
\hline$=27$ & 0.875 & 16.587 & 0.966 & 2.049 & 0.937 & 42.169 & 0.988 & 0.962 & 0.993 & 0.115 & 0.985 & 0.377 & 0.953 & 0.559 & 0.517 & 0.728 & NA \\
\hline$=28$ & 0.991 & 7.284 & 0.842 & 0.937 & 0.959 & 30.910 & 0.927 & 0.201 & 0.802 & 0.109 & 0.839 & 0.310 & 0.984 & 0.166 & 0.696 & 6.008 & 26.679 \\
\hline F29 & 0.991 & 5.791 & 0.985 & 0.148 & 0.988 & 24.933 & 0.995 & 0.143 & 0.948 & 0.022 & 0.950 & 0.207 & 0.997 & 0.146 & 0.675 & 4.835 & 31.384 \\
\hline$=30$ & 1.000 & 36.837 & 1.000 & 5.368 & 1.000 & 62.856 & 1.000 & 3.197 & 1.000 & 0.479 & 1.000 & 1.176 & 1.000 & 0.987 & 0.298 & 0.343 & $\mathrm{~N} / \mathrm{A}$ \\
\hline F31 & 0.959 & 15.883 & 0.964 & 1.980 & 0.982 & 39.478 & 0.994 & 0.960 & 0.993 & 0.153 & 0.967 & 0.678 & 0.982 & 0.645 & 0.389 & 0.743 & $\mathrm{~N} / \mathrm{A}$ \\
\hline F32 & 0.965 & 9.731 & 0.820 & 2.149 & 0.993 & 31.476 & 0.938 & 0.448 & 0.929 & 0.163 & 0.880 & 0.539 & 0.995 & 0.508 & 0.371 & 1.724 & N/A \\
\hline
\end{tabular}

"R2 "is the regression coefficient; " $\mathrm{K}$ " is the release rate constant for respective models; " $\mathrm{n}$ " is the diffusion exponent; "MDT" is the mean dissolution time, "DE" is the dissolution efficiency at $6 \mathrm{~h}$. N/A indicates that DE is not calculated as 90\% drug released before 6 h. F4, F5, F6, F7, F10, F13 and F21 released $90 \%$ drug within 2 h

sustain the drug release up to $12 \mathrm{~h}$ [34]. On the contrary, Pongjanyakul et al., reported that the drug release was decreased with increased proportions of GPS [7].

Release of Meclizine $\mathrm{HCl}$ from Compritol pellets was decreased with increase in concentration of Compritol. This release retardant effect was due to the presence of longer fatty acid chain length of Behenic acid (C22), providing higher degree of lipophilicity [32]. However, it was observed that Compritol failed to extend Meclizine $\mathrm{HCl}$ release up to $12 \mathrm{~h}$ which is in line with findings reported by Gu et al. [34].

CW is highly hydrophobic in nature with low wettability [19]. It controlled drug release extensively and imparted the highest retardation effect among the four lipids. CW is multi-constituent, containing alkyl esters of wax acids (80\%), particularly myricyl cerotate, free monohydric alcohols (10\%), resin and lactose [22]. In design of Meclizine $\mathrm{HCl}$ ER pellets, CW acted as effective release retardant. Since matrix pellets were devoid of channelling agents, absence of pores and cracks further inhibited drug release [19]. Although, it was reported in previous studies that ground CW (4-20\%) sustained release of theophylline for $3 \mathrm{~h}$ [5] and CW (25\%) resulted in extensive burst release within $1 \mathrm{~h} \mathrm{[22].}$

MCC is a well-known extrusion spheronization aid as it holds water like a sponge and inhibits separation of water from the solid blend during processing. When used with $\mathrm{CW}$, MCC formed irregularly shaped pellets because irregular particles of CW were distributed unevenly, causing hindrance during spheronization. Similar finding was also observed by Singh et al. [5]. MCC based pellets prolonged the drug release because they do not disintegrate. This decreases bioavailability of low aqueous soluble drugs [35]. 

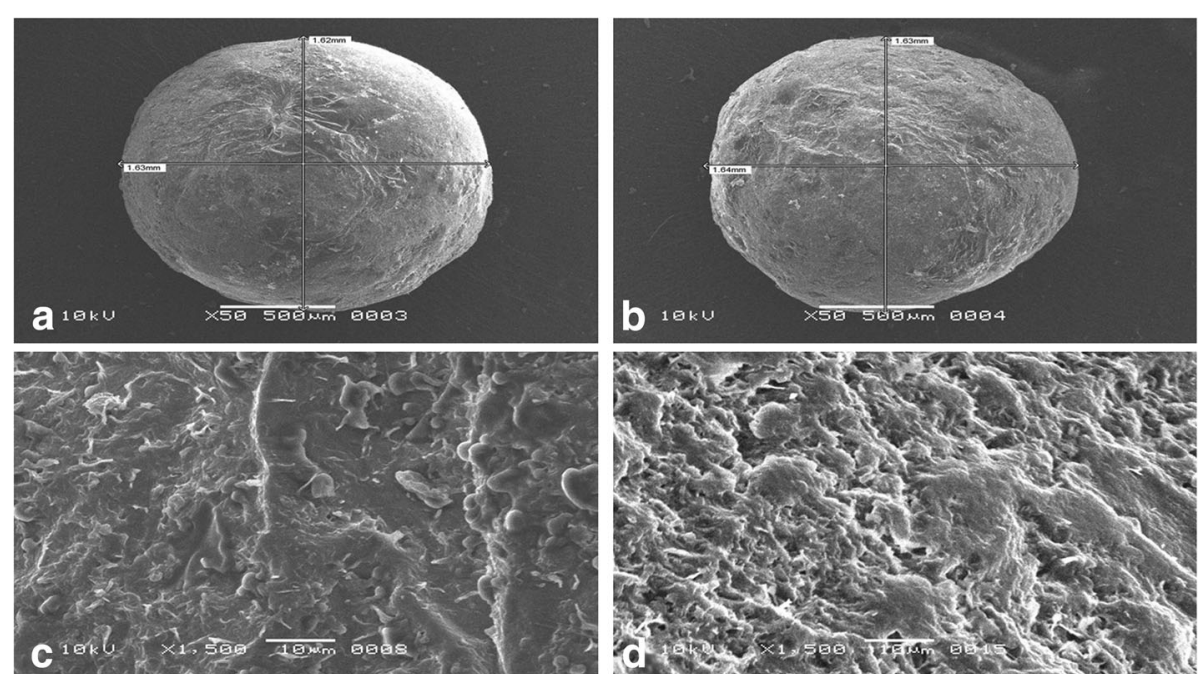

Fig. 5 SEM images showing combinations of Geleol and Compritol in drug/lipid ratio of (a) 1:2 (F17) (b) 1:3 (F18) (c) cross section of F17 (1:2) (d) cross section of F18 (1:3)

However, release of poorly soluble Meclizine $\mathrm{HCl}$ was unaffected by addition of $40 \%$ MCC.

The release profile of Meclizine $\mathrm{HCl}$ from each lipid was significantly different, indicating marked influence of physicochemical composition of lipids on drug release rate. It is clearly evident from the results of Group 1 that drug/lipid ratio of 1:0.5-1:1 for all lipids was insufficient for sustaining the Meclizine $\mathrm{HCl}$ release. Therefore, drug/lipid ratio was increased up to 1:3 in further groups to achieve the desirable extended release profile of Meclizine $\mathrm{HCl}$. Poor drug retardation effect in preparation of SR Milnacipran $\mathrm{HCl}$ was reported by Parjiya et al., when drug/lipid ratio was fixed at 1:1 during initial screening of Stearic acid, CW, Compritol and Bees wax, therefore, drug/wax ratio was increased from 1:1 to 1:1.25, 1:1.5 and 1:1.75. [24].

Irrespective of lipid type, its amount had an inverse influence on drug release i.e. rate of Meclizine $\mathrm{HCl}$ release decreased with higher level of lipids present in extrudedspheronized pellets with exception of Geleol. This might be due to the slower penetration of dissolution medium in matrices as a result of the increased lipophilicity of waxy substances [33]. Lipid content dependent drug release was more significant in case of $\mathrm{CW}$ as compared to others. CW is more lipophilic matrix that hardly allows water to penetrate into the pores of the matrix. It contains $5 \%$ resins, higher amount of fatty esters and lower hydroxyl number and free fatty acids resulting in
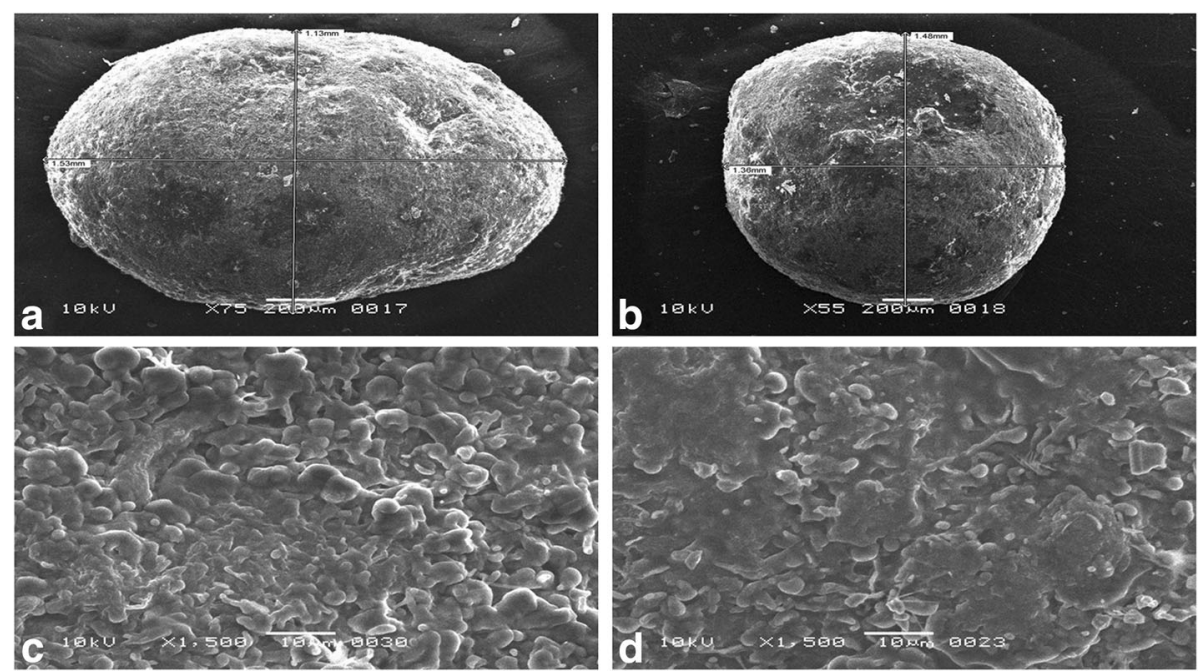

Fig. 6 SEM images showing (a) combination of Geleol ${ }^{\circ}$ and CW in drug/lipid ratio of 1:2 (F20) (b) combination of Geleol ${ }^{\circ}$, Compritol ${ }^{\circ}$ and CW in drug/lipid ratio of 1:2 (F28) (c) cross section of F20 (d) cross section of F28 

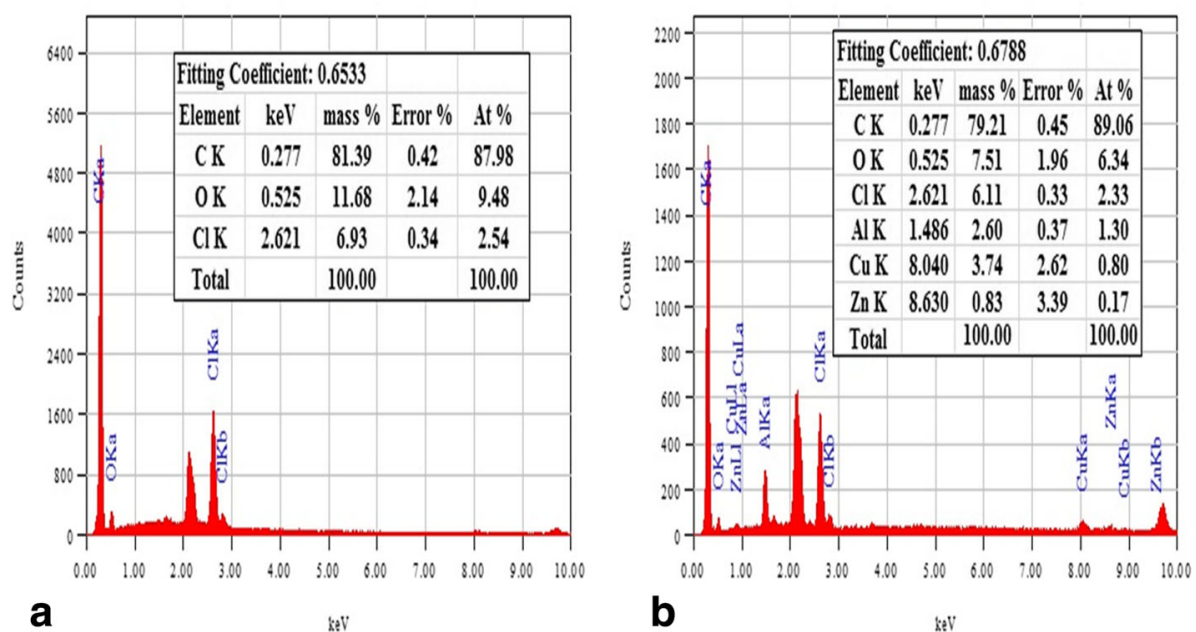

Fig. 7 EDS spectra showing (a) combination of Geleol ${ }^{\circ}$ and Compritol ${ }^{\circ}$ (F17) (b) combination of Geleol', Compritol and CW (F28)

reduced dissolution in acidic medium [20]. Geleol is more prone to hydration in dissolution medium because of hydroxyl groups [10].

Three combinations of lipids: (i) Geleol and Compritol (ii) Geleol and CW (iii) Geleol, Compritol and CW in different groups displayed extended release of antiemetic agent-Meclizine $\mathrm{HCl}$ up to $12 \mathrm{~h}$ with acceptable sphericity. In addition to MCC, Geleol was also added in each combination as it formed highly spherical pellets of Meclizine $\mathrm{HCl}$. Geleol and Compritol pellets in drug/lipid ratio of 1:2-1:3 presented desirable characteristics and extended drug release up to $12 \mathrm{~h}$ with the formation of smooth surface round pellets. The tortuosity of the matrix and drug diffusion path length were increased by combination of lipids and increment in lipid content, thus, reduced the diffusion and erosion from matrix. A similar observation is documented by Wadher et al., that release of metformin hydrochloride was more strongly retarded, when formulated with combination of waxes compared to metformin $\mathrm{HCl}$ formulation with single wax content because higher lipophilicity was observed in combination of waxes [33].

In sustained release dosage forms, Compritol is considered as an ideal excipient to substitute hydrophilic matrix, since, it is not associated with alcohol related dose dumping. It is highly resistant to physiological conditions ( $\mathrm{pH}$, digestion) and reduces burst effect of highly water soluble drugs [17]. Compritol provides stable release profile during storage [14]. Similar findings were noted by Jagdale et al., showing that Compritol is a mixture of mono (18\%), di (52\%) and tri (28\%) behenates of glycerol and is especially designed to produce sustained release of drugs which cannot be obtained from pure di or triglycerides [36].
This study shows that Geleol and CW pellets excessively retarded the release of Meclizine $\mathrm{HCl}$ in comparison to Geleol and Compritol pellets. Compritol has increased wettability in dissolution medium owing to its non-ionic surfactant characteristic with hydroxyl number 102.6 [20]. In CW matrix system, complete drug release is impossible because impermeable wax film entrap some fraction of dose [19].

Shape descriptors like aspect ratio and two dimensional shape factor were measured for single lipid and combinations of lipids extruded-spheronized pellets to analyse impact of lipid type, lipid amount and lipid combination on shape of Meclizine $\mathrm{HCl}$ pellets. Geleol formed highly spherical pellets of Meclizine $\mathrm{HCl}$ indicated by larger values of aspect ratio and two dimensional shape factor. Two dimensional shape factor was increased with greater amount of Geleol used in pellets. Precirol and Compritol formed spherical pellets with acceptable aspect ratio and shape factors. Insignificant differences in aspect ratio of Precirol and Compritol $^{\circ}$ pellets were observed when compared with Geleol. However, lower two dimensional shape factors indicated that Precirol and Compritol pellets were not perfectly round like Geleol pellets. Two dimensional shape factor is more sensitive to surface irregularities and to deviations from the ideal round shape as compared to aspect ratio [27]. Aspect ratio and two dimensional shape factor of CW pellets were beyond the acceptable lower limit indicating formation of irregular pellets. Two dimensional shape factor was decreased with increased content of $\mathrm{CW}$ indicating uneven surface of pellets. Geleol had the highest shape factors whereas, CW had the lowest shape factors, among all four lipids utilized for preparation of pellets. On the basis of findings of Group 1, Geleol was 
added in each lipid combination which resulted in acceptable shape descriptors.

SEM images further confirmed findings of stereomicroscopy. Combination of Geleol and Compritol indicated formation of spherical and intact pellets with smooth surfaces. Sphericity and surface smoothness of this lipid combination were independent of drug/lipid ratio. Higher lipid content formed dense network of lipid matrix. Combination of Geleol and CW formed highly rough pellets. Presence of Geleol failed to improve the surface roughness of CW pellets, clearly evident in SEM images. Irregular particles of $\mathrm{CW}$ were distributed unevenly which caused interruption during spheronization [5]. This surface roughness of CW was reduced by combination of Geleol, Compritol and CW in drug/lipid ratio of 1:2 (F28) and 1:3 (F29). SEM is coupled with EDS which is used to characterize elements in situ. In comparison to combination of Geleol and Compritol combination of Geleol, Compritol and CW showed additional peaks of aluminium, copper and zinc. These additional peaks may be due to vegetable origin of CW which is a natural ester lipid, obtained by extraction of carnauba palm [18]. This combination indicated presence of less oxygen when compared to combination of

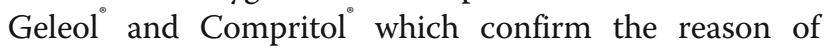
utilization of less granulating fluid during wet massing.

Meclizine $\mathrm{HCl}$ pellets were evaluated in different dissolution medium and $\mathrm{pH}$ dependent drug release was observed. Meclizine $\mathrm{HCl}$ is acidic salt of weakly basic drug having pKa 6.12. Therefore, its solubility and ionization are reduced at alkaline $\mathrm{pH}$ and increased at acidic $\mathrm{pH}$. This may be due to the conversion of the hydrochloride salt to its less soluble free base [15]. Similar pH dependent Meclizine $\mathrm{HCl}$ release was also observed by Mahrous et al. [2]

Release of Meclizine $\mathrm{HCl}$ from Compritol pellets was best described by Korsmeyer-Peppas model indicating nonFickian diffusion. Initially, Meclizine $\mathrm{HCl}$ was dissolved from external surface of pellets causing formation of pores in matrix. The matrix became soft with progressive dissolution leading to erosions, formation of channels and promoting penetration of medium to dissolve the drug. This dissolved drug diffused through the channels into the medium. This finding is consistent with previously reported studies [32, 33, 36, 37]. The value of $n$ is dependent on type of lipid and physicochemical properties of drug. CW pellets showed concentration independent release of Meclizine HCl. However, diffusion [19] and Fickian mechanism [20] associated with the use of $\mathrm{CW}$ matrices were also reported.

\section{Conclusions}

Single lipid matrix extruded-spheronized pellets of Geleol, Precirol and Compritol failed to extend Meclizine $\mathrm{HCl}$ release up to $12 \mathrm{~h}$, even in drug/lipid ratio of 1:2. Although the release of Meclizine $\mathrm{HCl}$ was extended up to $12 \mathrm{~h}$ with
$\mathrm{CW}$, but the pellets were irregularly shaped. This irregularity in shape was effectively controlled by addition of Geleol. Matrix extruded-spheronized pellets prepared with blends of (i) Geleol and Compritol, (ii) Geleol and CW (iii) Geleol, Compritol and CW successfully extended release of Meclizine $\mathrm{HCl}$ up to $12 \mathrm{~h}$. These lipids combinations in ratio of $1: 2$ can be effectively used to prepare ER matrix pellets of Meclizine $\mathrm{HCl}$. Lipid combination of Geleol $^{\circ}$ and Compritol (F17) formed highly spherical pellets with smooth surfaces and successfully sustained the release of Meclizine $\mathrm{HCl}$ up to $12 \mathrm{~h}$. These lipids combinations can be effectively employed to design extended release pellet formulation of Meclizine $\mathrm{HCl}$ by extrusion spheronizaton technique, for the control of vertigo, pruritus, nausea and dizziness up to extended period of time.

\section{Abbreviations \\ ASTM: American Society of Testing and Materials; CW: Carnauba Wax; DE: Dissolution Efficiency; ER: Extended Release; GB: Glyceryl behenate; GMS: Glyceryl monostearate; GPS: Glyceryl palmito Stearate; HCl: Hydrochloric Acid; ICH: International Conference on Harmonization; MC: Moisture Content; MCC: Microcrystalline Cellulose; MDT: Mean Dissolution Time; RH: Relative Humidity; SR: Sustained Release}

\section{Acknowledgments \\ Authors are thankful to Morgan Group for kindly providing GMS, Compritol and Precirol and Ali Gohar Pharmaceuticals (Pvt) Ltd. for generously gifting antiemetic agent Meclizine $\mathrm{HCl}$.}

\section{Funding}

Not applicable.

\section{Availability of data and materials \\ The datasets analyzed during the current study available from the corresponding author on reasonable request.}

\section{Authors' contributions}

MHS, RIY and FQ conceived and designed the research idea. FQ, MIN and KA collected and reviewed the literature. FQ, MIN and KA conducted the study. FQ and MA analyzed the data. FQ, MHS, RIY and MA interpreted the findings. MHS, RIY and MA contributed ingredients / reagents / instruments / analysis tools. FQ drafted the manuscript. MHS, RIY and MA reviewed / revised the research article. MHS and RIY supervised the study. All authors read and approved the final manuscript.

\section{Competing interests}

The authors declare that they have no competing interests.

\section{Consent for publication \\ Not applicable.}

Ethics approval and consent to participate

Not applicable.

\section{Publisher's Note}

Springer Nature remains neutral with regard to jurisdictional claims in published maps and institutional affiliations.

\section{Author details}

'Department of Pharmaceutics, Faculty of Pharmacy \& Pharmaceutical Sciences, University of Karachi, Karachi 75270, Pakistan. ${ }^{2}$ Research Institute of Pharmaceutical Sciences, Department of Pharmacognosy, Faculty of Pharmacy \& Pharmaceutical Sciences, University of Karachi, Karachi 75270, Pakistan. 
Received: 4 November 2016 Accepted: 2 April 2017 Published online: 12 April 2017

\section{References}

1. Wang Z, Lee B, Pearce D, Qian S, Wang Y, Zhang Q, Chow MS. Meclizine metabolism and pharmacokinetics: formulation on its absorption. J Clin Pharmacol. 2012:52:1343-9.

2. Mahrous GM, Shazly GA, Ibrahim MA. Formulation and evaluation of meclizine $\mathrm{HCl}$ orally disintegrating tablets. Bull Pharm Sci. 2011;34:141-8.

3. Symphonyhealth: http://symphonyhealth.com/wp-content/uploads/2015/ 05/Top-200-Drugs-of-2014.pdf (accessed: 25.03.17)2017.

4. PfizerProductsAntivert: https://www.pfizerpro.com/pfizer-products. (accessed: 25.03.17) 2017

5. Singh R, Poddar $S$, Chivate A. Sintering of wax for controlling release from pellets. AAPS PharmSciTech. 2007:8:E175-83.

6. Kranz H, Jürgens K, Pinier M, Siepmann J. Drug release from MCC-and carrageenan-based pellets: experiment and theory. Eur J Pharm Biopharm. 2009;73:302-9.

7. Pongjanyakul T, Medlicott NJ, Tucker IG. Melted glyceryl palmitostearate (GPS) pellets for protein delivery. Int J Pharm. 2004;271:53-62.

8. Hamdani J, Moës AJ, Amighi K. Physical and thermal characterisation of Preciro $^{\circledast}$ and Compritol $^{\circledR}$ as lipophilic glycerides used for the preparation of controlled-release matrix pellets. Int J Pharm. 2003;260:47-57.

9. Cheboyina S, Chambliss WG, Wyandt CM. A novel freeze Pelletization technique for preparing Matix pellets. Pharm Technol. 2004;28:98-111.

10. Cheboyina S, Wyandt CM. Wax-based sustained release matrix pellets prepared by a novel freeze pelletization technique: II. In vitro drug release studies and release mechanisms. Int J Pharm. 2008;359:167-73.

11. Roblegg E, Jäger E, Hodzic A, Koscher G, Mohr S, Zimmer A, Khinast J. Development of sustained-release lipophilic calcium stearate pellets via hot melt extrusion. Eur J Pharm Biopharm. 2011;79:635-45.

12. Rahman MA, Ahuja A, Baboota S, Bali V, Saigal N, Ali J. Recent advances in pelletization technique for oral drug delivery: a review. Current drug delivery. 2009;6:122-9.

13. Nasiri Ml, Yousuf Rl, Shoaib MH, Fayyaz M, Qazi F, Ahmed K. Investigation on release of highly water soluble drug from matrix-coated pellets prepared by extrusion-spheronization technique. J Coat Technol Res. 2016:1-12.

14. Becker K, Salar-Behzadi S, Zimmer A. Solvent-free melting techniques for the preparation of lipid-based solid oral formulations. Pharm Res. 2015;32:1519-45.

15. Gao Z, Yu L, Clark S, Trehy M, Moore T, Westenberger B, Buhse L, Kauffman J, Bishop B, Velazquez L. Dissolution Testing for bioavailability of over-thecounter (OTC) drugs - a technical note. AAPS PharmSciTech. 2015;16:1227.

16. Shukla D, Chakraborty S, Singh S, Mishra B. Lipid-based oral multiparticulate formulations-advantages, technological advances and industrial applications. Expert opinion on drug delivery. 2011;8:207-24.

17. GattefosseProducts: http://www.gattefosse.com/en/applications/ ?administration-route,oral,substained-release. (accessed:25.03.17) 2017.

18. Pezzini BR, Grossl AD, Muraro A, Bazzo GC, Soares L. Formulation and in vitro assessment of sustained release matrix tablets of atenolol containing Kollidon SR and carnauba wax. Afr J Pharm Pharmacol. 2014:8:1058-65.

19. Reza MS, Quadir MA, Haider SS. Comparative evaluation of plastic, hydrophobic and hydrophilic polymers as matrices for controlled-release drug delivery. J Pharm Pharm Sci. 2003;6:282-91.

20. Özyazıcı M, Gökçe EH, Ertan G. Release and diffusional modeling of metronidazole lipid matrices. Eur J Pharm Biopharm. 2006;63:331-9.

21. Reddy KR, Mutalik S, Reddy S. Once-daily sustained-release matrix tablets of nicorandil: formulation and in vitro evaluation. AAPS PharmSciTech. 2003:4:480-8.

22. Quadir MA, Rahman MS, Karim MZ, Akter S, Awkat M, Reza M. Evaluation of hydrophobic materials as matrices for controlled-release drug delivery. Pak J Pharm Sci. 2003:16:17-28.

23. Wilson B, Babubhai PP, Sajeev MS, Jenita JL, Priyadarshini BSR. Sustained release enteric coated tablets of pentaprazole: formulation, in vitro and in vivo evaluation. Acta Pharma. 2013;63:131-40.

24. Parejiya PB, Barot BS, Patel HK, Mehta DM, Shelat PK, Shukla A. Release modulation of highly water soluble drug using solid dispersion: impact of dispersion and its compressed unit. Journal of Pharmaceutical Investigation. 2014;44:163-75.

25. USP 38 NF 33: U.S. Pharmacopeia National Formulary. Rockville: The United States Pharmacopeial Convention; 2015.
26. Chamsai B, Sriamornsak P. Novel disintegrating microcrystalline cellulose pellets with improved drug dissolution performance. Powder Technol. 2013;233:278-85.

27. Podczeck F, Rahman S, Newton J. Evaluation of a standardised procedure to assess the shape of pellets using image analysis. Int J Pharm. 1999;192:123-38.

28. Kitak T, Govedarica B, Srčič S. Physical properties of pharmaceutical pellets. Chem Eng Sci. 2013;86:50-60.

29. FDADissolution: http://www.accessdata.fda.gov/scripts/cder/dissolution/ index.cfm (accessed 11.03.16). 2016

30. Qazi F, Shoaib MH, Yousuf RI, Qazi TM, Mehmood ZA, Hasan SMF. Formulation development and evaluation of Diltiazem $\mathrm{HCl}$ sustained release matrix tablets using HPMC K4M and K100M. Pak J Pharm Sci. 2013;26:653-63.

31. Costa P, Lobo JMS. Modeling and comparison of dissolution profiles. Eur J Pharm Sci. 2001;13:123-33.

32. Abd-Elbary A, Tadros Ml, Alaa-Eldin AA. Sucrose stearate-enriched lipid matrix tablets of etodolac: modulation of drug release, diffusional modeling and structure elucidation studies. AAPS PharmSciTech. 2013;14:656-68.

33. Wadher KJ, Kakde RB, Umekar MJ. Formulations of sustained release metformin hydrochloride tablet using combination of lipophilic waxes by melt granulation technique. Afr J Pharm Pharmacol. 2010:4:555-61.

34. Gu X, Fediuk DJ, Simons FER, Simons KJ. Evaluation and comparison of five matrix excipients for the controlled release of acrivastine and pseudoephedrine. Drug Dev Ind Pharm. 2004;30:1009-17.

35. Kranz H, Jurgens K, Pinier M, Siepmann J. Drug release from MCC- and carrageenan-based pellets: experiment and theory. Eur J Pharm Biopharm. 2009;73:302-9.

36. Jagdale S, Patil S, Kuchekar B, Chabukswar A. Preparation and characterization of Metformin hydrochloride- Compritol 888 ATO solid dispersion. J Young Pharm. 2011;3:197-204.

37. Yan X, He H, Meng J, Zhang C, Hong M, Tang X. Preparation of lipid aspirin sustained-release pellets by solvent-free extrusion/spheronization and an investigation of their stability. Drug Dev Ind Pharm. 2012;38:1221-9.

\section{Submit your next manuscript to BioMed Central and we will help you at every step:}

- We accept pre-submission inquiries

- Our selector tool helps you to find the most relevant journal

- We provide round the clock customer support

- Convenient online submission

- Thorough peer review

- Inclusion in PubMed and all major indexing services

- Maximum visibility for your research

Submit your manuscript at www.biomedcentral.com/submit
) Biomed Central 